\title{
Nanotheranostics
}

\author{
2021; 5(1): 73-89. doi: $10.7150 /$ ntno.49614
}

Review

\section{Multifunctional microfluidic chip for cancer diagnosis and treatment}

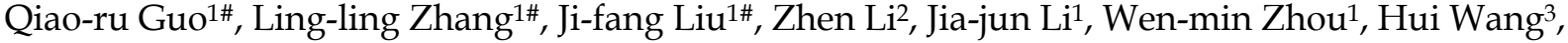

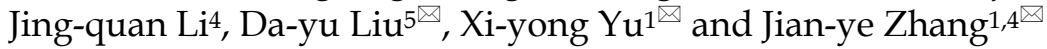 \\ 1. Key Laboratory of Molecular Target \& Clinical Pharmacology and the State Key Laboratory of Respiratory Disease, School of Pharmaceutical Sciences \& the \\ Fifth Affiliated Hospital, Guangzhou Medical University, Guangzhou, P.R.China. \\ 2. Department of Gastroenterology, Qilu Hospital, Cheeloo College of Medicine, Shandong University, Jinan, P.R.China. \\ 3. Guangzhou Institute of Pediatrics/Guangzhou Women and Children's Medical Center, Guangzhou Medical University, Guangzhou, P.R.China. \\ 4. The First Affiliated Hospital, Hainan Medical University, Haikou, P.R.China. \\ 5. Department of Laboratory Medicine, Guangzhou First People's Hospital, School of Medicine, South China University of Technology, Guangzhou, \\ P.R.China. \\ \#These authors contributed equally to this work. \\ $\square$ Corresponding authors: Jian-ye Zhang, E-mail: jianyez@163.com; Xi-yong Yu, E-mail: yuxycn@aliyun.com; Da-yu Liu, E-mail: eydyliu@scut.edu.cn.
}

( ) The author(s). This is an open access article distributed under the terms of the Creative Commons Attribution License (https://creativecommons.org/licenses/by/4.0/). See http://ivyspring.com/terms for full terms and conditions.

Received: 2020.06.19; Accepted: 2020.10.08; Published: 2021.01.01

\begin{abstract}
Microfluidic chip is not a chip in the traditional sense. It is technologies that control fluids at the micro level. As a burgeoning biochip, microfluidic chips integrate multiple disciplines, including physiology, pathology, cell biology, biophysics, engineering mechanics, mechanical design, materials science, and so on. The application of microfluidic chip has shown tremendous promise in the field of cancer therapy in the past three decades. Various types of cell and tissue cultures, including 2D cell culture, 3D cell culture and tissue organoid culture could be performed on microfluidic chips. Patient-derived cancer cells and tissues can be cultured on microfluidic chips in a visible, controllable, and high-throughput manner, which greatly advances the process of personalized medicine. Moreover, the functionality of microfluidic chip is greatly expanding due to the customizable nature. In this review, we introduce its application in developing cancer preclinical models, detecting cancer biomarkers, screening anti-cancer drugs, exploring tumor heterogeneity and producing nano-drugs. We highlight the functions and recent development of microfluidic chip to provide references for advancing cancer diagnosis and treatment.
\end{abstract}

Key words: Microfluidic chip; Cancer; Preclinical model; Drug screening; Biomarker; Nanoparticle

\section{Introduction}

The conventional approach of cancer treatment includes surgery, radiotherapy, chemotherapy, and targeted therapy. These approaches have significant curative effect in the early stage of management, but cancer relapse usually occurs after a period of treatment. Moreover, the "one-size-fits-all" treatment works differently in different patients [1]. Every type of cancer needs a unique treatment regimen [2]. Therefore, an efficient, rapid and accurate tool is needed to realize the precise diagnosis and treatment for each patient.

Microfluidic chip is an approach which can manipulate fluids on a microscopic scale, thus controlling cell culture relevant parameters to better simulate the microenvironment of tumor tissues in vivo. More precisely, the microscale structure of microfluidic chip can delicately operate cells, the multiplexing microstructures are easy to conduct high-throughput analysis, the control of microfluid is advantageous to mimic internal fluidic environment and specific material properties can better mimic the tumor microenvironment. It has a great potential to become a powerful auxiliary equipment to realize in precision medicine [3], particularly in the fields of tumor organoid culture, screening of anticancer drugs, detection of cancer biomarkers, single-cell sequencing and preparation of nanoparticles (NPs). In light of these functions, microfluidic chip combined 
with downstream analysis can identify molecular, cellular and biophysical features of cancer progression [4]. Due to its customizable characteristics, microfluidic devices can meet the needs of various researches, thus has tremendous prospect for development. In this manuscript, we will highlight the multi-function of microfluidic chip and summarize the new technologies to develop novel microfluidic chips.

\section{Functional diversity of microfluidic chip}

\section{The establishment of preclinical models}

Preclinical models are needed for exploring the key molecular and cellular mechanisms of cancers. Microfluidic chip cancer models are often used in testing the efficacy and assessing the safety of the potential anticancer agents or drug combination regimens. Microfluidic devices can not only automate the culture of tumor cells, but also realize multi-cell co-culture under the biomimetic condition by controlling fluid flow rate and other parameters to form cancer tissue organoids. Therefore, microfluidic chips have great potentials in the establishment of preclinical models.

\section{Types of preclinical cancer models}

Conventional two-dimensional (2D) cancer cell cultures are convenient, but they cannot reflect the complex information of tumor microenvironment (TME) [5]. Compared with 2D cell culture, the threedimensional (3D) cancer cell culture, including 3D hydrogel and 3D spheroids, can better mimic TME, especially the 3D spheroid, which exhibits the complex cellular heterogeneity and the physiologically relevant cell-cell and cell-extracellular matrix (ECM) interactions [6]. However, 3D hydrogel cell culture lacks tissue-tissue interface and require large amount of cells. Tumor spheroids in the traditional sense are still unable to reproduce the mechanical forces, such as fluid shear stress which tumor tissues are subjected to [4]. Using microfluidic devices to preform 3D cancer cell culture could solve this problem [7-12].

Animal models still play important roles in preclinical trials. The development of therapeutic strategies cannot advance without the results of animal studies [13]. However, establishing a proper animal model is very costly and time consuming. Nevertheless, animal models usually lack the native human tissue-microenvironment. Some kinds of animal models, such as nude mouse, are also lack of immune response. Indeed, trials in animal models cannot usually correctly predict the future responses of drug therapy in human [14].

Due to the disadvantage of these preclinical models, tumor organoids models have attracted more and more attention. Organoids is a kind of 3D cell culture that generated from stem cells or organ progenitors, including human pluripotent stem cells (PSCs) [15-17] and cancer stem cells [18-20]. Organoids consist of multiple organ-specific cell types and are able to recapitulate some specific function of the organ [21]. Tumor organoids derived from cancer stem cells and other cells existing in TME can mimic tumor characteristics in vitro, as well as the heterogeneity in tumor. Taken together, tumor organoids have enormous potential in cancer modeling.

Cell culture and cancer modeling at the 2D or 3D level can easily be realized in microfluidic chip. Using the microfluidic chip, the 2D culture, 3D hydrogel, 3D tumor spheroid, as well as tumor organoids could provide reliable data in a high-throughput and automated way. Therefore, microfluidic chip makes it more widespread application in the development of preclinical cancer model (Figure 1). How does microfluidic chip mimic tumor microenvironment and establish cancer models? Thus, we will introduce a few examples in the next part.

\section{Cancer models on microfluidic chip}

The secondary tumors formed through metastasis are the main causes of cancer mortality. Tumor progression and metastasis is a stepwise cascade of events that include the primary tumor growth, angiogenesis, tumor cells invasion, intravasation, extravasation and metastasis to secondary sites [22, 23]. Therefore, it is a great challenge to set up an appropriate cancer model on microfluidic chips.

In the past decades, many studies have shown several types of human organ chip models. Hassel et al. reported an orthotopic cancer organ chip model of non-small-cell lung cancer (NSCLC) to recapitulate tumor growth, dormancy and the therapeutic response to tyrosine kinase inhibitors (TKIs) associated with breathing motions [24].

Microfluidic devices which used to mimic cancer metastasis process are usually applied to several cell types in order to culture two or more organoids. Different organoids are separated by some specific biomaterials, such as polydimethylsiloxane (PDMS), and connected with each other by channels and controllable fluids. $\mathrm{Xu}$ et al. designed and constructed a multi-organ microfluidic chip to mimic lung cancer metastasis to the brain, bone and liver. In this platform, organoids were divided into different chambers, including upstream lung organoid and three downstream organoids. Different types of cells were seeded in each chamber to culture different organoids and each organoid were linked by side 
channels. The culture medium flowed through microvascular channels to simulate blood circulation. At the same time, a circulating vacuum was applied to mimic the physiological breathing (Figure 2a) [25]. This system provided a physiologically relevant context to recapitulate the complex process of lung cancer metastasis and help us to effectively explore the underlying mechanism of lung cancer metastasis.

In another research, a microfluidic bone chip was used to study breast cancer metastasized to bone marrow. Based on the principle of the simultaneous growth dialysis, the space of bone-on-a-chip (BC) contained two areas for osteoblastic tissue growth and culture medium flow (Figure 2b) [26]. This design mimicked a natural bone microenvironment and allowed mineralized osteoblastic tissue to form an unprecedented thick layer without artificial scaffolds or in vivo growth step. Furthermore, researchers co-cultured the metastatic human breast cancer cells with the osteoblastic tissue developed in the BC and observed several important features of bone metastasis in breast cancer. The BC has the potential to become a powerful tool in the study of cancer bone metastasis in vitro.

In addition to the cancer metastasis model, microfluidic devices can be designed into a variety of preclinical models to cater for the needs of various studies, including the microfluidic chip of human 3D microvasculature assay to study cancer cell extravasation [27, 28], a microfluidic platform to study the metastatic cancer cell matrix invasion [29] and the microfluidic blood-tumor barrier model [30]. The microfluidic chip models used to simulate the different stages of tumor progression to metastasis are summarized in Table 1.

Of course, cancer models are not simply made to replicate the physiological and pathological status. They played a much more profound role in screening of anticancer drugs and the detection and discovery of biomarkers. Large-scale production of reliable microfluidic tumor organoid chip models can achieve rapid and high-throughput drug screening and real-time dynamic monitoring of disease signals in a visual and quantitative way.

\section{D printed microfluidic chip and cancer models}

The integration between 3D bioprinting and microfluidic chip has given microfluidic chip greater potential to model cancers. Traditionally, in cancer modeling on chip, microfabrication such as micromachining, photolithography and injection molding, are used in the fabrication of microfluidic chips [31]. These methods have high resolution and accuracy, but their high cost, complex process and difficult reproducibility greatly limited the development of microfluidic chip [3]. The emerging of 3D printing technology greatly simplifies the fabrication process of microfluidic chips.

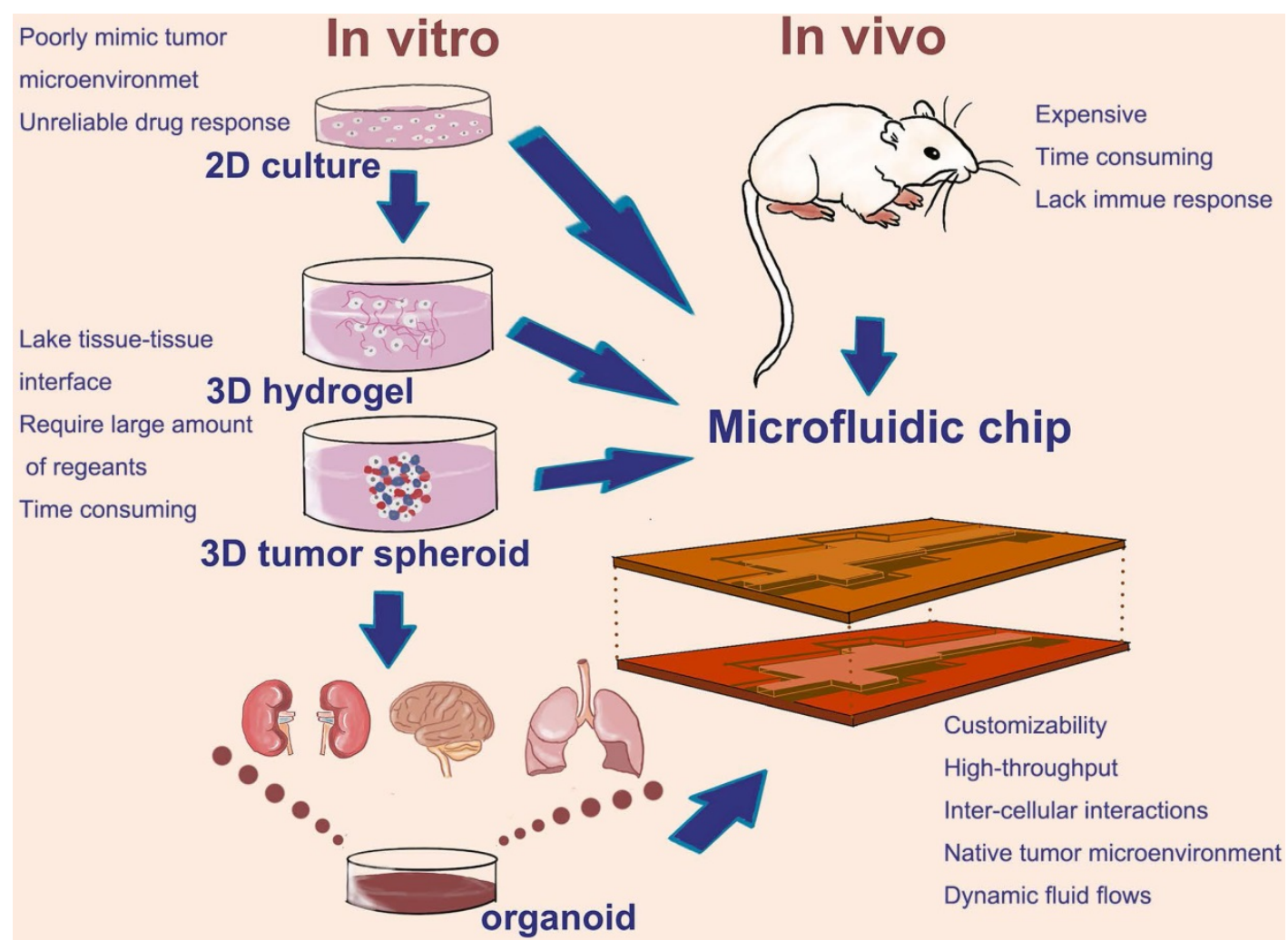

Figure 1. Common types and the development of cancer preclinical model; Animal models, 2D culture, 3D culture, as well as tumor organoid which development in recent years, have playing an important role in cancer preclinical modeling. Microfluidic chip as a promising technology can flexible integrin these cell culture modes on a chip. 
Table 1. List of microfluidic cancer model about mimicking the cascade events of tumor progression

\begin{tabular}{|c|c|c|c|c|}
\hline Aim of study & Culture model type & Cancer type & Notes & Ref. \\
\hline Tumor-like transformation & 2D culture & Lung cancer & $\begin{array}{l}\text { Studying tumor-like transformation of bronchial epithelial cells that are } \\
\text { continuously exposed to cigarette smoke extracts }\end{array}$ & [168] \\
\hline $\begin{array}{l}\text { Lesions of ductal carcinoma } \\
\text { in situ }\end{array}$ & 3D culture & Breast cancer & $\begin{array}{l}\text { Tumor spheroid co-cultured with mammary fibroblasts and human mammary } \\
\text { ductal epithelial cells to mimic 3D structural organization and } \\
\text { microenvironment }\end{array}$ & [169] \\
\hline Angiogenesis & $3 \mathrm{D}$ culture & - & $\begin{array}{l}\text { Using a newly Sphero-IMPACT platform to culture 3D tumor spheroid and } \\
\text { monitor angiogenesis, tumor cell migration and invasion }\end{array}$ & [9] \\
\hline Extravasation & 3D culture & Breast cancer & $\begin{array}{l}\text { Setting up a 3D microvascular network to study human metastatic breast } \\
\text { cancer cell extravasation }\end{array}$ & {$[28]$} \\
\hline Extravasation & 3D culture & - & $\begin{array}{l}\text { Establishing a human microcirculation model to dynamically monitor the } \\
\text { extravasation of several tumor cell line }\end{array}$ & {$[27]$} \\
\hline Extravasation & 3D culture & Breast cancer & $\begin{array}{l}\text { Establishing a microvascular network to study the extravasation potential of } \\
\text { breast cancer cells in a hypoxia environment }\end{array}$ & [170] \\
\hline Invasion & 3D culture & Lung cancer & $\begin{array}{l}\text { Using composite hydrogel microfibers to quantitatively analyze invasion } \\
\text { behavior of tumor cells }\end{array}$ & [171] \\
\hline Invasion & 3D culture & Breast cancer & $\begin{array}{l}\text { Formed a tumor-macrophage bidirectional crosstalk system to evaluate the } \\
\text { antagonistic effect of the system on anticancer drugs }\end{array}$ & [172] \\
\hline $\begin{array}{l}\text { Metastatic cancer cell matrix } \\
\text { invasion }\end{array}$ & 3D culture & Breast cancer & $\begin{array}{l}\text { Cancer cells co-cultured with endothelial to explore the matrix invasion } \\
\text { behavior of metastatic breast cancer cells }\end{array}$ & [29] \\
\hline Invasion and migration & 3D culture & Breast cancer & $\begin{array}{l}\text { Tumor cells co-cultured with patient-derived fibroblast cells and evaluate } \\
\text { tumor cell migration and invasion under the influence of tumor-stroma } \\
\text { interactions }\end{array}$ & [173] \\
\hline Invasion and migration & $3 \mathrm{D}$ culture & Breast cancer & $\begin{array}{l}\text { Through polyelectrolyte complex coacervation process, } 3 \mathrm{D} \text { collagen barrier was } \\
\text { formed around cancer cell to mimic the basement membrane and observe cells } \\
\text { migration and invasion }\end{array}$ & [174] \\
\hline Migration & 3D culture & Breast cancer & $\begin{array}{l}\text { Tumor spheroid co-cultured with endothelial cells. Using 3D photopatterning } \\
\text { to confine cells into gelatin methacrylate (GelMA) hydrogel structures }\end{array}$ & [175] \\
\hline Metastasis & 3D culture & Breast cancer & $\begin{array}{l}\text { Developing a spontaneous "bone-on-a-chip" to study bone metastasis in breast } \\
\text { cancer }\end{array}$ & {$[26]$} \\
\hline Metastasis & 2D culture & Breast cancer & $\begin{array}{l}\text { Developing a microfluidic blood-tumor barrier model to study brain metastasis } \\
\text { in breast cancer }\end{array}$ & [30] \\
\hline Metastasis & 3D culture & Colon cancer & $\begin{array}{l}\text { Developing a multiple 3D tissue construction to study liver metastasis in colon } \\
\text { cancer }\end{array}$ & [176] \\
\hline Metastasis & 3D culture & Colorectal cancer & $\begin{array}{l}\text { Using 3D photopatterning technique, researchers developed a microfluidic } \\
\text { device that houses lung and liver organoid to mimic lung and liver metastasis } \\
\text { in colorectal cancer }\end{array}$ & [177] \\
\hline Stroma-mediated cell motility & 3D culture & Pancreatic cancer & Tumor spheroid co-cultured with stellate cells in a 7-channel microfluidic plate & {$[10]$} \\
\hline Intercellular interactions & 3D culture & Liver cancer & Tumor cell co-cultured with stellate cells & {$[8]$} \\
\hline
\end{tabular}

In addition to manufacture microfluidic device, 3D printing technology can be applied to construct organ-on-a-chip and biological scaffolds on chips [32, 33]. Four common methods of 3D printing used in bioprinting and chip fabrication including stereolithography (SLA) bioprinting, extrusion bioprinting, inkjet bioprinting and laser-assisted bioprinting. The application of 3D printing provides a new method for cell seeding on microfluidic chips without the need for the time-consuming manual seeding and the redundancy pumping seeding [34]. Not only that, 3D printing allows the simultaneous process of living cells and biomaterials, which provides tumor model with fine, replicating ECM on chips [35]. Using specific bio-ink formulations, $3 \mathrm{D}$ bioprinting is able to build different complex channels or ECM on chip and preserve the heterogeneity of the primary tumor [34, 36]. In fact, for the organoid or biological scaffolds constructed by bio-printer, applying the mechanical force generated by fluid is able to simulate the metastasis of cancer cells in vivo. It has been reported that cancer cells tend to migrate towards the direction of liquid flow, and the microfluidic chip provides a mechanical force to mimic TME [37]. These merits allow 3D printing to enhance the function of microfluidic chips, and 3D printing gradually became an important method in cancer modeling and drug screening on chips [38-41]. Several representative studies on the use of 3D printed microfluidic device for cancer modeling or diagnosis in the past five years was summarized in Table 2.

\section{The detection of cancer biomarkers}

Cancer biomarkers could be circulating tumor cells (CTCs), circulating tumor DNA (ctDNA), exosomes, non-coding RNA (ncRNA) and various cellular metabolites or proteins [42-44], of which the precise detection of biomarkers contributed to early diagnosis and grading of cancers [45]. Conventional cancer screening methods, such as invasive tissue biopsy or medical imaging, are costly and complex. Recently, microfluidic chip is catching up to overcome these obstacles. 

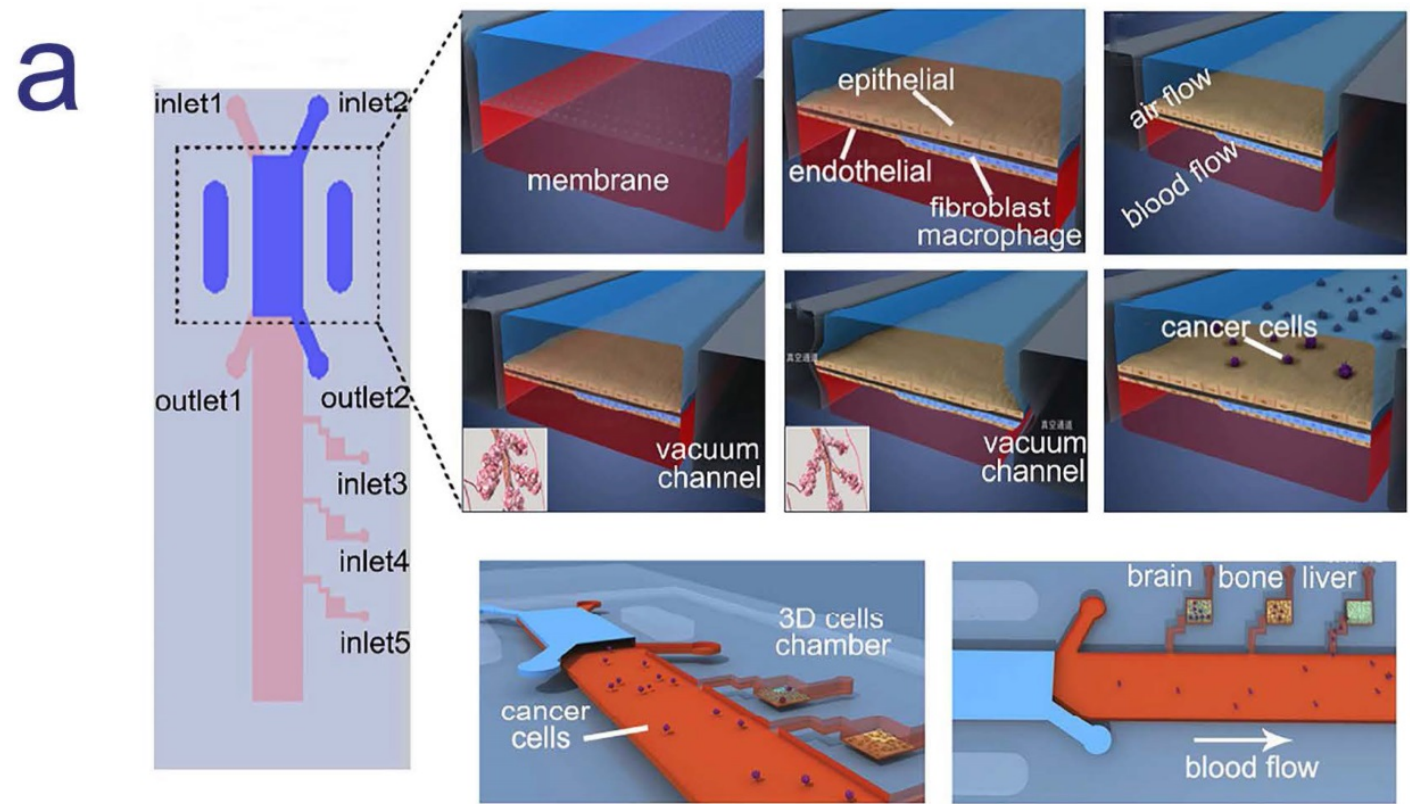

b
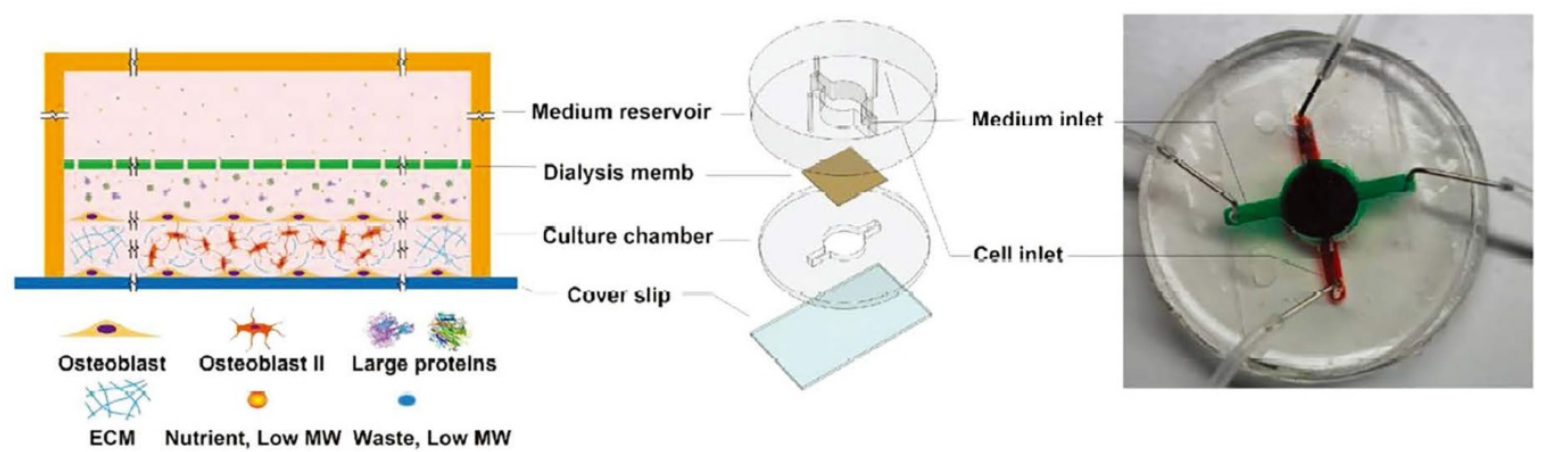

Figure 2. Two different cancer models based on microfluidic chips to mimic cancer metastasis; a. a multi-organ microfluidic chip to mimic lung cancer metastasis to the brain, bone and liver; b. a cancer model based on microfluidic chip for the study breast cancer metastasized to bone marrow. a. Copyright American Chemical Society, 2016. Reproduced with permission from reference [25]; b. Copyright Wiley, 2018. Reproduced with permission from reference [26].

Table 2. List of cancer related 3D printed microfluidic chip during the past five years

\begin{tabular}{|c|c|c|c|c|}
\hline Research contents & $\begin{array}{l}\text { 3D printing } \\
\text { method }\end{array}$ & Function of 3D printing & Notes & Ref. \\
\hline $\begin{array}{l}\text { Compared with the suitability of SLA and PloyJet } \\
\text { method in printing microstructure of microfluidic } \\
\text { device. }\end{array}$ & $\begin{array}{l}\text { SLA and PolyJet } \\
\text { bioprinting }\end{array}$ & $\begin{array}{l}\text { Printed microstructure of microfluidic } \\
\text { device }\end{array}$ & 3D tumor spheroid; Liver cancer & [178] \\
\hline $\begin{array}{l}\text { Constructed a 3D microfluidic model to conduct the } \\
\text { pharmacodynamic tests of an anti-CD } 147 \text { monoclonal } \\
\text { antibody. }\end{array}$ & $\begin{array}{l}\text { Integrated } \\
\text { printing }\end{array}$ & 3D cell printing & 3D culture; Liver cancer & [39] \\
\hline $\begin{array}{l}\text { Constructed a metastasis model on chip to investigate } \\
\text { bone metastasis in breast cancer. }\end{array}$ & - & Fabricated the cast molds & 3D culture; Breast cancer & {$[26]$} \\
\hline $\begin{array}{l}\text { Breast cancer cell morphology, migration, and the } \\
\text { interaction with bone matrix on chip. }\end{array}$ & SLA & $\begin{array}{l}\text { Constructed a 3D biomimetic bone } \\
\text { matrix }\end{array}$ & 3D culture; Breast cancer & [179] \\
\hline $\begin{array}{l}\text { Explored the effect of variable peptide-engineered } \\
\text { exosomes in cancer immunotherapy. }\end{array}$ & - & Fabricated microfluidic culture chip & $\begin{array}{l}\text { The yield and purity of engineered } \\
\text { exosomes were improved, and the } \\
\text { operation time was reduced. }\end{array}$ & [180] \\
\hline $\begin{array}{l}\text { A low-cost with ultralow detection limit immunoarray } \\
\text { was developed to analyze the expression of multiple } \\
\text { biomarker proteins in serum samples from cancer } \\
\text { patients. }\end{array}$ & SLA & Fabricated microfluidic chip & $\begin{array}{l}\text { Detected prostate cancer biomarker } \\
\text { proteins in serum; Low sample } \\
\text { volume. }\end{array}$ & {$[181]$} \\
\hline $\begin{array}{l}\text { Developed a "Lab-on-a-printer" and demonstrated its } \\
\text { function by printed type I collagen seeded with liver } \\
\text { cancer cells. }\end{array}$ & Inkjet bioprinting & $\begin{array}{l}\text { Fabricated chip and formed patterned } \\
\text { biological structure by printing bio-ink }\end{array}$ & $\begin{array}{l}\text { This platform integrated microfluidic } \\
\text { mixer with inkjet dispenser on a chip. }\end{array}$ & [182] \\
\hline
\end{tabular}




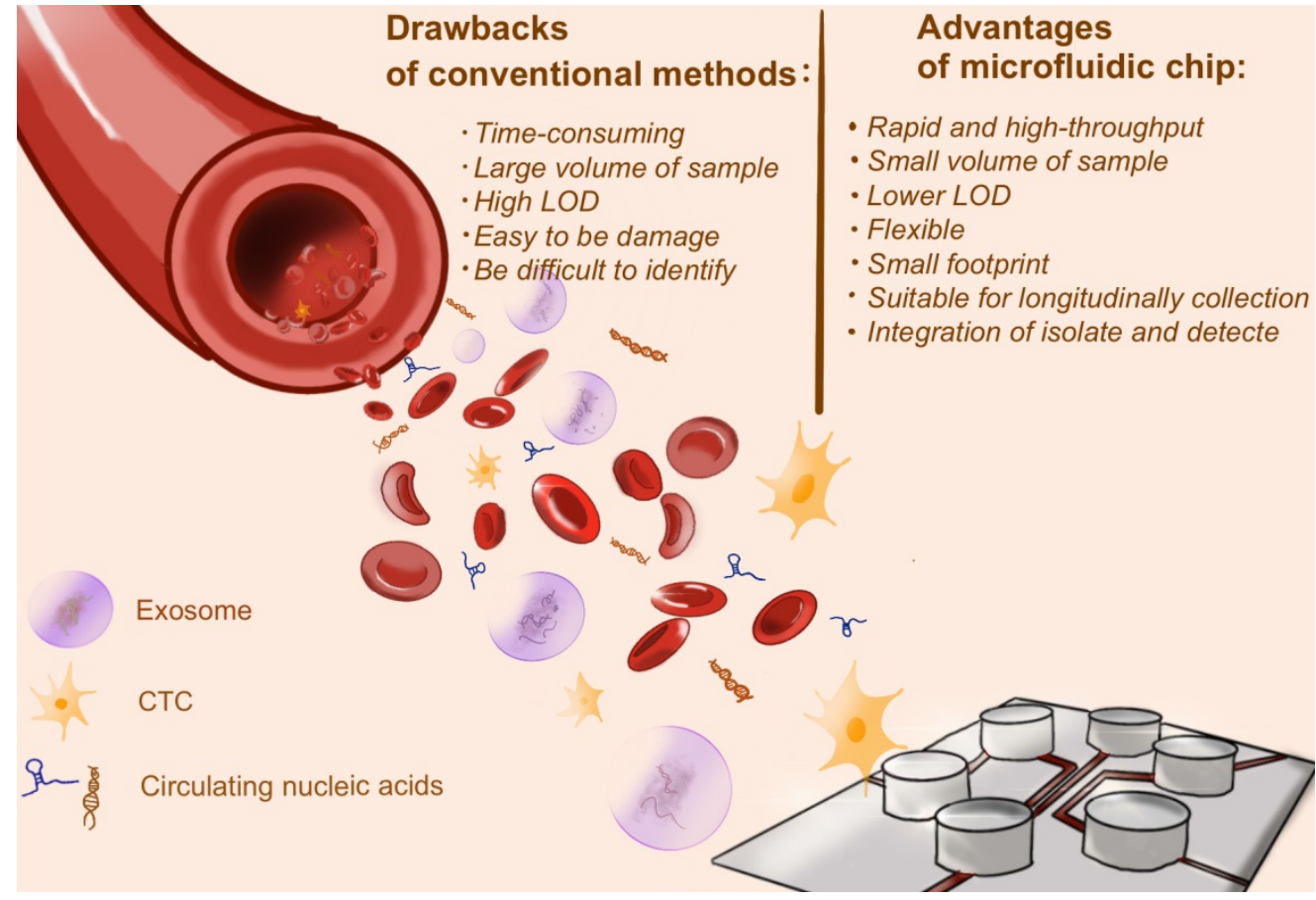

Figure 3. The advantages of microfluidic chip for cancer biomarker detection. Conventional methods to detect cancer biomarkers, including invasive tissue biopsy or medical imaging, are costly and time-consuming, and even need large volume of sample. Microfluidic chip, as a burgeoning approach, shows great potential in biomarkers detection. The merits are described in the figure above.

\section{On-chip CTC detection}

CTCs are tumor cells that shed from solid tumors into peripheral blood. Several studies indicated that CTCs are closely associated with cancer metastasis. The significance of using CTCs as cancer biomarker is that CTCs have the ability to reflect the real-time tumor burden and explore tumor heterogeneity. However, detecting CTCs from blood is extremely challenging for three reasons. First, CTCs are so rare: it could only be one CTC per $10^{9}$ blood cells in the patients' peripheral blood [46]. Therefore, it might require a large quality of blood samples. It is extremely low limit of detection (LOD) to draw CTCs from blood samples. Second, CTCs varies in size and morphology, making it difficult to identify. Third, CTCs are easily damaged in the process of identification [42].

The existing gold standard for CTCs separating and counting is CellSearch $\odot$ system, which is based on immunoaffinity for isolation and fluorescence for cell counting [47]. In this system, epithelial cell adhesion molecule (EpCAM) as a selection tag for CTCs, anti-EpCAM conjugated magnetic beads are used to capture and isolate CTCs [48]. In fact, immuno-magnetic capture is a very classical method and EpCAM is a common antigen in CTCs capturing. In addition to CellSearch $\odot$, immune isolation is used in most CTCs separation platform, such as MagSweeper [49] and many microfluidic CTCs isolation platform.
However, the antigen-based selection of CTCs has some drawbacks. First, it has been shown in some studies that cell metabolic and protein composition may alter because of the use of antibody against EpCAM [50]. Second, antibody binding to cell surface antigens may cause cytotoxic effects [51]. Third, the number of CTCs is sometimes underestimated due to antigenic bias. Moreover, both EpCAM-positive or EpCAM-negative CTCs are circulating in blood [52]. Therefore, besides the antigen-based selection, based on some physical properties, such as the size [53,54], shape [55], electrical impedance [56] or inertial focusing of cells, these have also proved to be effective. In addition to these methods, Ganesh et al. proposed another approach for isolation of CTCs. According to the Warburg effect, glycolysis is upregulated in primary and metastatic cancers [57]. Glucose is metabolized into pyruvate and lactate, leading to the low $\mathrm{pH}$ in extracellular environment of cancer cells compared to normal cells [58]. Researchers used the $\mathrm{pH}$ differences between normal cells and cancer cells to set up a microfluidic chip based on $\mathrm{ZnO} \mathrm{pH}$ sensors for possible identification of CTCs in blood [59]. Even the antigen-independent method still have some drawbacks (for example, some studies have shown that CTCs are similar or smaller in size to leukocytes; the effect of hydrogen, oxygen and elevated temperatures generated by the use of dielectrophoretic method cannot be ignored), it still can cover some shortage of the antigen-based selection of CTCs to some extent. 
Table 3. List of several representative CTCs isolation microfluidic chip in the past decades

\begin{tabular}{|c|c|c|c|c|c|c|}
\hline $\begin{array}{l}\text { Microfluidic } \\
\text { technologies }\end{array}$ & $\begin{array}{l}\text { Antigen- } \\
\text { based } \\
\text { selection }\end{array}$ & $\begin{array}{l}\text { Antigen- } \\
\text { independen } \\
\text { t selection }\end{array}$ & Basic properties & Advantages & Ref. & $\begin{array}{l}\text { Application } \\
\text { in cancer } \\
\text { diagnosis }\end{array}$ \\
\hline CTC-chip & $\sqrt{ }$ & & $\begin{array}{l}\text { The laminar flow of blood cells through the } \\
\text { anti-EpCAM antibody-coated microposts in CTC-chip } \\
\text { to capture CTCs. }\end{array}$ & $\begin{array}{l}\text { Less damage to rare cells; } \\
\text { Simplicity; Versatility; One-step } \\
\text { manipulate. }\end{array}$ & [183] & [184] \\
\hline $\begin{array}{l}\text { The herringbone } \\
\text { chip }\end{array}$ & $\sqrt{ }$ & & $\begin{array}{l}\text { The microvortices produced by herringbone grooves } \\
\text { within the chip wall adequately mix the blood cells, } \\
\text { increasing the interaction between CTCs and the } \\
\text { anti-coated surface in chip. }\end{array}$ & $\begin{array}{l}\text { Higher blood volume throughput; } \\
\text { high capture efficiency and purity. }\end{array}$ & [185] & [186-190] \\
\hline $\begin{array}{l}\text { Geometrically } \\
\text { enhanced } \\
\text { differential } \\
\text { immunocapture } \\
\text { (GEDI) }\end{array}$ & $\sqrt{ }$ & & $\begin{array}{l}\text { The streamline deformation can help the target CTCs } \\
\text { come into full contact with the immune coating on the } \\
\text { wall; relative obstacle alignment uses the displacement } \\
\text { generated by the impact between cells and obstacles to } \\
\text { separate cells of different sizes. }\end{array}$ & $\begin{array}{l}\text { High binding avidity and } \\
\text { specificity; high cell capture } \\
\text { efficiency and purity. }\end{array}$ & [191] & - \\
\hline $\begin{array}{l}\text { NanoVelcro } \\
\text { Microfluidic Device }\end{array}$ & $\sqrt{ }$ & & & & & \\
\hline CTC-ichip & $\sqrt{ }$ & $\sqrt{ }$ & $\begin{array}{l}\text { The negative depletion of normal blood cells: using } \\
\text { deterministic lateral displacement to isolate nucleated } \\
\text { cells; using inertial focusing to align nucleated cells; } \\
\text { deflecting and collecting magnetically tagged cells. }\end{array}$ & $\begin{array}{l}\text { Automation; high-throughput; } \\
\text { compatible with high-definition } \\
\text { imaging and single-cell analysis. }\end{array}$ & {$[60]$} & [192-194] \\
\hline Spiral chip & & $\sqrt{ }$ & $\begin{array}{l}\text { Spiral chip generates the inertial and Dean drag forces } \\
\text { with continuous flow in curved channels to separate } \\
\text { cells. The principle of separation is based on the } \\
\text { physical difference between CTCs and blood } \\
\text { constituents. }\end{array}$ & $\begin{array}{l}\text { Stable streamlines distribution; } \\
\text { high flow rates; ultra-high } \\
\text { throughput; simplify the assistant } \\
\text { procedures in clinical experiments; } \\
\text { Less damage to CTCs. }\end{array}$ & [195] & {$[196,197]$} \\
\hline Straight chip & & $\sqrt{ }$ & $\begin{array}{l}\text { The straight chip take advantage of cells inertial } \\
\text { migration in the straight microchannel to separate CTCs } \\
\text { with high purity by manipulating flow rate ratio. }\end{array}$ & $\begin{array}{l}\text { High purity collection; high } \\
\text { recovery rate; high throughput; } \\
\text { predictable and tunable cutoff size. }\end{array}$ & [198] & [199] \\
\hline $\begin{array}{l}\text { Nanotube-CTC- } \\
\text { Chip }\end{array}$ & & $\sqrt{ }$ & $\begin{array}{l}\text { Carbon nanotube surfaces and microarray batch } \\
\text { manufacturing is combined to capture and separate } \\
\text { CTCs; Red blood cell lysis (RBCL) and preferential } \\
\text { adherence can enrich CTCs. }\end{array}$ & $\begin{array}{l}\text { High capture efficiency; high } \\
\text { purity. }\end{array}$ & [200] & - \\
\hline
\end{tabular}

Nowadays, more and more studies have applied not only a single CTCs capturing method, but also a hybrid method combining these two classical modes, among which CTC-iChip is a representative CTCs isolation platform. The main design principle of CTC-iChip is the high-efficiency negative depletion of blood cells. At the same time, CTC-iChip utilized the inertial forcing to align nucleated cells, deflect and collect magnetically tagged cells. The untagged CTCs isolated from CTC-iChip are easy to purify the high-quality RNA, which is particularly suitable for downstream transcriptomic analysis [60]. Yan and colleagues developed a "Rhipsalis (Cactaceae)"-like Hierarchical Structure on chip. This platform combined two approaches based on cell size or immunoaffinity to capture CTCs by modifying specific antibody on the micropillars [61]. Both methods have high capture efficiency and are wildly used in many microfluidic devices. The downside is the high production cost and time-consuming.

In order to achieve more efficient CTCs capture and isolation, more and more studies tend to combine traditional techniques (such as immune-magnetic capturing) with microfluidic chip or image processing during these years [62]. It is worth to mention that microfluidic shows great application potential in CTCs capturing due to its multiplexing and simplicity. Various CTCs isolation platforms based on microfluidic chips have appeared one after another, such as CTC-chip, CTC-ichip, spiral chip, GEDI and so on. In Table $\mathbf{3}$, we summarize several representative CTCs isolation microfluidic chip in the past decades.

Microfluidic chip is usually used for isolating and enumerating CTCs. However, with the in-depth study on CTCs, scientists gradually found that besides evaluating the number of CTCs in a certain volume of blood to determine tumor burden, CTCs also play a key role in cancer metastasis and reflect the tumor heterogeneity. For this reason, after isolating CTCs, the downstream analysis of CTCs can better provide molecular characteristic. For example, protein analysis and single cell sequencing can help to increase the recognition of cancer subpopulation and provide a powerful reference for personalized therapy. Microfluidic Western blotting has been reported to profiling protein expression in patientderived single CTCs [63]. In another study, combining with multiplex surface-enhanced Raman spectroscopy (SERS) nanovectors on microfluidic chip was used to identify subtypes of CTCs in accordance with the clinically relevant surface protein composite spectral signatures [64]. More remarkably, using single-cell sequencing on CTCs or other cancer 
relevant cells on chips have been wildly used, which will be elaborated in the section 2.4.

\section{On-chip exosome detection}

Exosome is one of the extracellular vesicles (EV) and the size ranges between 30-100 nm [65]. Exosomes act as communicators between different cells by transferring a variety of cargoes, such as mRNA, ncRNA and proteins [66]. In recent years, exosome has been considered as a promising biomarker for cancer diagnosis and prognosis. Changes in the expression of certain cargoes in exosome tend to suggest tumor status or indicate some changes taken place in tumor.

Cancer derived exosomes are often extracted from various body fluids, such as serum, ascites, and pleural effusion [67]. The most commonly used exosome separation method is to use ultracentrifugation (UC) [68], which is time- and reagentsconsuming. Although various new methods emerged in recent years, there is not much change in exosome separation and detection [69-71]. Microfluidic chip can not only efficiently complete the separation and detection of exosomes, but also integrate these two techniques on a single chip, which greatly simplify the procedure.

Microfluidic chip is like a framework that could be flexibly used by researchers based on their study needs. There have been various methods to separate and detect tumor derived exosomes on chips. The separation methods include immunoaffinity-based separation [72-74], nanomembranes filter [75], dielectrophoretic (DEP) separation [76], lateral displacement and acoustic fluid separation [77]. The detection techniques include fluorescence detection, electrochemical detection [78] and mass spectrometry [79]. Moreover, there are integrated chips that combined exosome separation and detection in the last few years. For example, $\mathrm{Xu}$ et al. set up a two-stage microfluidic platform which integrated a staggered Y-shaped micropillars and an Indium Tin Oxide (ITO) electrode [80]. This platform achieved separation of exosomes separation by the newly staggered Y-shaped micropillars array to create anisotropic flow and promote the full binding of exosomes to antibody modified magnetic beads. Following capture, using a cascading ITO electrode to detect the captured exosomes and realize signal transduction [80].

The main challenges of the exosomes isolation are to achieve high-throughput, high recovery rate and low damage [81] for rapid detection. Although great achievement has been made in the field of exosome detection on chips in the past years, there is still much space for improvement in the existing techniques.

\section{On-chip ctDNA and ncRNA detection}

Circulating nucleic acids are released from the apoptotic cancer cells or tumor exosomes that entered blood circulation [82]. The levels of circulating nucleic acids reflect the tumor burden or malignant progression [83]. Circulating nucleic acids including cell-free DNA (cfDNA), mRNA and ncRNA, et al. ctDNA is a sub-class of cfDNA which carries information of mutations and often detected in the peripheral blood of cancer patients [84]. ncRNA is a kind of RNA that has no coding function, including microRNA (miRNA), long noncoding RNA (lncRNA), circular RNA (circRNA), et al. Many studies have shown that ncRNAs are functional regulatory molecules that involved in cancer progression [85-88].

The equipment used for extracting ctDNA through liquid biopsy needs to meet the ctDNA size ranged 50-150 bp and with high recovery, minimal interference, and high reproducibility [89]. Microfluidic chip provides an automated platform that greatly improved the efficiency of ctDNA extraction. The solid-phase extraction technique was applied to a microfluidic chip to activate the polymer surface to generate $-\mathrm{COOH}$ by $\mathrm{UV} / \mathrm{O} 3$. The cfDNA was extracted from patients' plasma samples through the specific immobilization buffer, achieving the purpose of high recovery and low cost [90].

Furthermore, point-of-care (POC) cancer diagnostic is one of the goals in the development of microfluidic chip. Since the half-life of cfDNA are very short, the rapid and automatic techniques used to isolate cfDNA from plasma with low degradation are urgently needed. Kim and colleagues developed a fully automated microfluidic platform that can purify cfDNA from cancer patient's plasma in a short time (30 min). This device is based on the electromagnetically actuated diaphragm valves. It integrated the function of plasma separation, residual protein lysis, cfDNA elution, therefore greatly improved the time of cfDNA isolation from patients' blood.

Many studies have demonstrated the tremendous application of using the combination of microfluidic chip and digital polymerase chain reaction (PCR). The reason is that compared to the commercial PCR assay, digital PCR technique on chips is more accurate, high throughput and less timeconsuming [91-94]. Digital PCR on microfluidic chips could be used to directly investigate the association among cancer ncRNA [95] and DNA methylation [96] from liquid biopsy. For example, Moltzahn et al. developed a microfluidic platform with multiplex qRT-PCR to profile miRNA signature in the serum of patients with prostate cancer for diagnosis and 
prognosis [97]. Wang et al. used droplet digital PCR (ddPCR) and achieved lung cancer related miRNA qualification [95].

PCR technology is a gold standard for miRNA measurement, but there are some limitations, including the design of suitable primers and the error-prone amplification steps. Recently, the use of the clustered regularly interspaced short palindromic repeats (CRISPR)-associated methods towards the detection of nucleic acid have emerged [98, 99]. By using different CRISPR-associated (Cas) effectors, different types of nucleic acid can be detected. Cas13a is an RNA-guided RNase which can produce multiple cleavage sites in nontarget single-stranded RNAs $[100,101]$. Based on this characteristic, Cas13a can be used to amplify nucleic acid signals without the synthetic nucleic acid amplification steps [102]. On microfluidic chips, the enzyme Cas13a, the targetspecific CRISPR RNA (crRNA) and the labeled reported RNA (reRNA) combined with an electrochemical biosensor was used to detect miRNA in the serum samples of patients who suffered from brain tumors [103]. When the serum sample contained target miRNA, the Cas13a/ crRNA complex caused reRNA collateral cleavage due to the "collateral activity". The change of reRNA was detected by the electrochemical biosensors and the current signal readout is inversely proportional to the concentration of miRNA in the serum sample [103]. It is worth mentioning that the detection time of this method is short (less than $4 \mathrm{~h}$ ) and the needed sample volume is less than $0.6 \mu \mathrm{L}$. All in all, the combination of microfluidic device and CRISPR technique provides a new idea for the detection of circulating nucleic acids and holds promise for the future of POC testing and personalized therapy.

\section{Anti-cancer drug screening and nano-drug preparation}

\section{Anti-cancer drug screening on microfluidic chip}

According to the culture modes, the microfluidic models for drug screening are categorized as single cell line culture, multi-cell line culture to mimic TME and patient-derived tumor organoid. In addition to evaluating the efficacy, chemosensitivity and safety of a single drug, microfluidic chip can also provide patients with a reasonable drug combination regimen according to their own conditions. These functions allow the determination of specific types of drugs in advance for possible emergence of drug resistance.

\section{Drug screening on microfluidic cancer models}

Setting up a microphysiological system (Bodyon-a-Chip) is one of the ways to screen drugs and determine the mode of administration. Inhalation therapy is an important treatment for lung diseases, in which drugs are inhaled directly to the desired sites with less drug accumulation at nontargeted sites [104]. A microfluidic platform with multi-organ and breathable lung chamber was reported for the screening and development of inhaled and intravenous drugs [105]. In this model, the lung compartment was linked with the liver and tumor compartment by channels. It is worth mentioning that researchers modified the traditional lung air-liquid interface (ALI) model and designed an "ALI bridge" to mimic lung breathing mechanisms (Figure 4a). Through the "ALI bridge", the platform can confirm whether inhaled therapeutic drugs can be used for treating systemic disease. In addition, researchers used the improved hanging drop method to introduce several types of cells and create 3D structure of breast-cancer tumor [105]. Based on this platform, researchers can easily compare the cytotoxic effects of curcumin administered by intravenous injection and inhalation.

Utilizing patient derived tumor tissue for microfluidic-based chemo-sensitivity assay has become an important means for personalized therapy. Astolfi and colleagues described a method, named micro-dissected tissues (MDTs), in which patient derived tumor tissues were sectioned to submillimeter size [106]. MDTs were trapped by sedimentation in square-bottom wells, because trapping cells by sedimentation can shield MDTs from excessive shear stress and provide more stable environment for imaging and observation (Figure $4 b$ ). A high-grade serous ovarian cancer patient tissue sample was used to conducting drug screening on the chip. Compared with the clinical follow-up, it was found that the positive response measured by microfluidic chip in vitro was consistent with the clinical response of patient, indicating that the platform can identify potential responder [106].

In fact, the generation of quiescent microvascular networks always precedes the nascent tumors during tumorigenesis [107, 108], However, some studies showed that excessive tumor growth and insufficient vascular growth occurred when endothelial cells and tumor cells were seeded at the same time. By adjusting the seeding order of tumor and endothelial cells, Shirure et al. developed a patient-derived organoid microfluidic platform that can simultaneously test chemotherapeutics (such as paclitaxel) and anti-angiogenics (such as bevacizumab). After 7 days culture, the microvascular network was mature and patient-derived organoids were transplanted to the vicinity of the microvascular network, which reproduced the intravasation of tumor cells [109]. Moreover, through the 
microvascular networks, drug testing based on this platform better replicated the physiological delivery of drugs to tumor.

\section{Drug screening in single-cell analysis}

Anti-cancer drug screening by bionic microfluidic chip is often limited by the collective cell behaviors. Due to the hallmark of heterogeneity in tumor, various cell sub-populations exist in tumors, and some of them are the key factor for cancer metastasis, drug resistance and tumor relapse. Analysis focusing on each individual cell is increasingly important.
Considerable evidence suggests that microfluidic chip has become a state-of-the-art drug screening approach in the single-cell level. A variety of methods based on microfluidic devices have been developed for flexible use in the single-cell manipulation, such as: optical tweezers [110], droplets [111], magnetic beads [112], and deterministic lateral displacement (DLD) separation method [113]. Identifying tumor cells by electrical sensing modality (such as measuring cell impedance magnitude) [114, 115], Raman or fluorescence spectroscopy [116] and polymerase chain reaction (PCR) were developed.
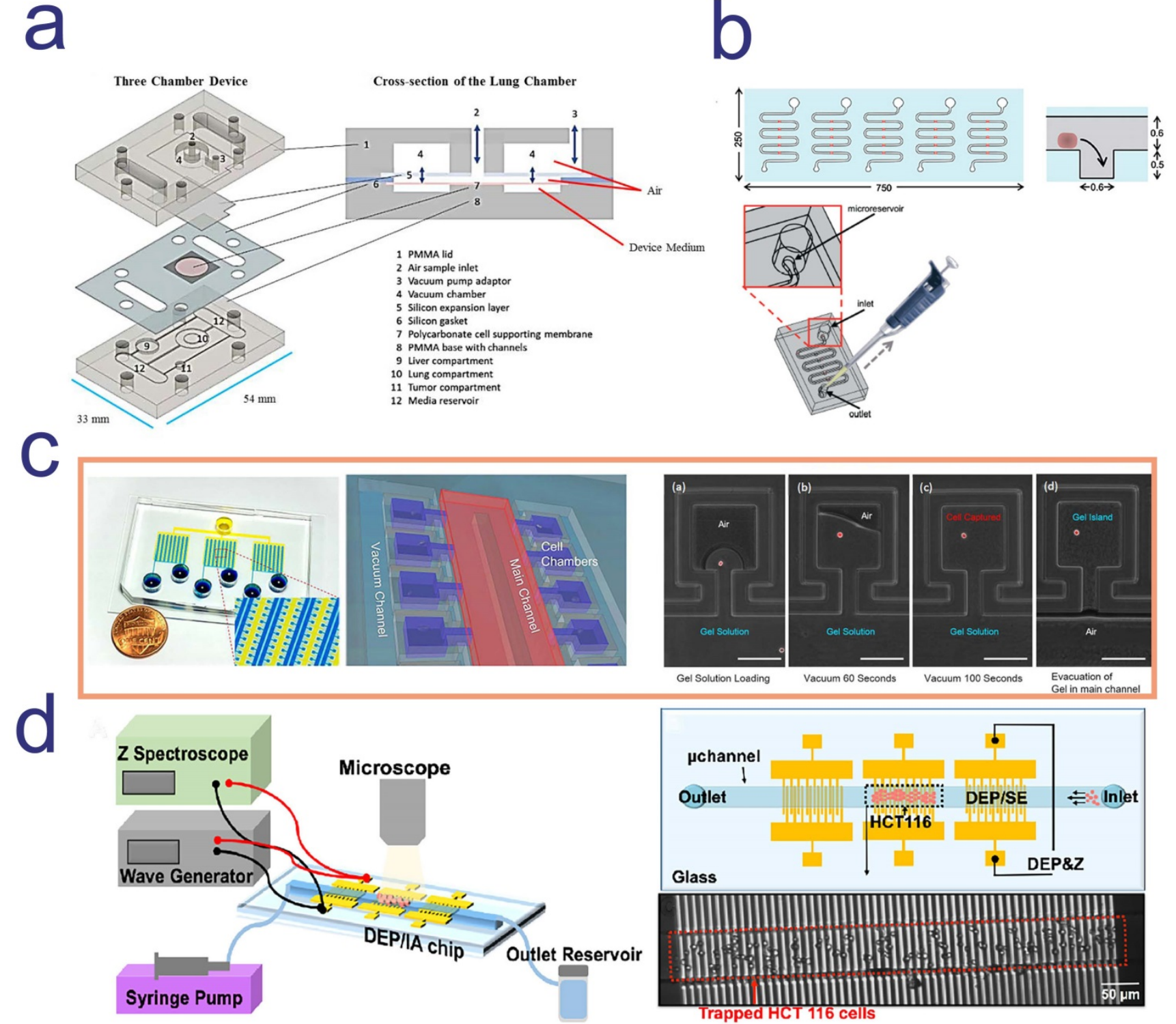

Figure 4. Four microfluidic chip for anti-cancer drug screening; a. a three-chamber microfluidic chip consists with a breathable lung compartment, which can better mimic lung breathing mechanisms and easily compare the cytotoxic effects of drug administered by intravenous injection and inhalation; b. MDT was trapped by sedimentation in square-bottom wells to avoid excessive shear stress and obtain more stable imaging observation; c. Each island of this microfluidic device was formed by gel that pumping out of the main channel and single cells were loaded into each island and maintained high viability; d. dielectrophoresis (DEP)/impedance analysis (IA) chip was consists in this microfluidic platform, which can realize high-throughput single cell capture. a. Copyright Wiley, 2020. Reproduced with permission from reference [105]; b. Copyright The Royal Society of Chemistry, 2015. Reproduced with permission from reference [106]; c. Copyright The Royal Society of Chemistry, 2016. Reproduced with permission from reference [117]; d. Copyright American Chemical Society, 2019. Reproduced with permission from reference [115]. 
For example, a microfluidics 3D gel-island chip was reported to isolate single cell, categorize the cancer cell state and detect single cell drug susceptibility. 3D gel-island was a 3D ECM cell culture environment and each island were formed by gel that pumping out of the main channel. Single cells were loaded into each island and maintained high viability (Figure 4c) [117]. Utilizing this device, researchers monitored the drug resistant behavior of cells with single cell resolution after treating doxorubicin and cisplatin. After the administration, breast cancer stem-like cells and non-stem-like cells shows different drug resistant behavior, in which stem-like cells were more resistant than non-stem-like cells [117]. This result indicated that drug sensitivity was correlated with the change of status of cells and confirmed the great potential of using microfluidic single cell analysis platform for anti-cancer drug screening.

Drug testing methods often require high sensitivity in screening drugs in specific cell population and monitor cell status in limited patients tumor tissue sample or blood [118]. Aside from the costly label reagents, the expensive optical equipment and complex microfabricated channel structures, a new microfluidic device using patient biopsies for drug screening has attracted attentions. The biggest characteristic of this platform is the label-free capture and analysis of targeted cells in real-time. Using the powerful dielectrophoresis (DEP) technique, highthroughput cell capture can be simply performed (Figure 4d). In addition, real-time and continuous cellular behavior analysis generated thousands of data point for each therapeutic-cell interaction [115].

\section{The preparation of nano-drugs}

Some chemotherapeutic and imaging agents with low molecular weight cannot be retained effectively in blood and tumor. NPs are an excellent tool to attack the targeted cancer cells while retain in healthy tissues. The enhanced permeability and retention (EPR) effect allows solid tumors selectively accumulate NPs [119]. Small size NPs can passively accumulate in tumors according to EPR effect and can also actively bound to target cells by surface target ligand modification [120]. Nanomaterial encapsulation of drugs can reduce toxicity and achieve drug tolerance, while encapsulated imaging agents or modify fluorescent probe are contributed to diagnostics and biological distribution [121].

Compared with the classical batch technology, the microfluidic process are particularly appealing in the synthesis of nanomaterials and the preparation of nano-drugs [122]. Micromixer integrated with microfluidic chip provides an efficient mixture in a small length scale; the precise control of temperature and kinetics ensure the uniformity of nano-drugs. In addition, microfluidic device can also satisfy the in-situ monitoring of NPs formation. For example, adjusting the flow rate ratio and different lipid components can precisely controlled the NPs size and surface properties [123]. Microfluidic devices are now capable of preparing a variety of NPs, including lipid-based nanobiomaterials [124-126], polymeric nanoparticles [127-129], lipid-polymer hybrid nanoparticles [130, 131] and engineered exosomes [132, 133].

Since the flow state of the fluid on microfluidic device is different from that of the turbulence in large-scale channels, its laminar flow state and mass transfer is completely dependent on diffusion [134]. Therefore, the mixing step on chip often needs external mechanism, such as electrokinetic [135, 136], magnetic $[137,138]$ and the special design of channel geometry mentioned above [139], and often lacks the dynamic control of fluid interface. Under this premise, the combination of hydrodynamic focusing (HF) device and microfluidic chip can be a good choice for the synthesis of NPs. In simple terms, the HF process is a high flow rate sheath fluid compresses a low flow rate central fluid [140]. In practice, the precise control of relative flow rate of chemical components can regulate the concentration and solubility [129], thus the synthesis of NPs in microfluidic hydrodynamic flow focusing (HFF) device will produce a more uniform particle size distribution. Ran et al. developed an HFF platform for single-step preparation of multifunctional liposomes. In this platform, the plain liposomes, PEGylated liposomes and the folic acid modified liposomes that encapsulated fluorescence dye were synthesized and showed reliable stability in serum. The liposomes modified targeting ligand (folic acid) demonstrated stronger selectivity and internalization in 3D tumor spheroid model [141]. Conventional production of multifunctional liposomes often requires tedious post-processing, but this platform greatly reduced the difficulty of liposomal preparation and increased the uniformity of liposomes. More than that, a number of studies in recent years had proven that this technique has tremendous potential for high-throughput production of NPs [142, 143].

Molecular engineering of exosome is a new avenue for drug delivery. In fact, endogenous drug delivery system (DDS) often outperforms synthetic nanomaterials in terms of retention time and targeting. Red blood cell membrane, white blood cell membrane, cancer cell membrane (CCM) and other natural cell membranes have a better biocompatibility in vivo and are good raw materials for NPs synthesis 
[144-147]. It is worth mentioning that exosome membrane (EM) can also be used to prepare NPs after engineering. Conventional microfluidic devices have low efficiency in preparation of nanoparticle of natural membrane sources. Liu and colleagues applied microfluidic sonication to assemble tumorderived EM-coated and CCM-coated poly (lactic-coglycolic acid) (PLGA) NPs. EM- and CCM- coated NPs have the ability to enhance targeting efficacy because there are some specific surface antigens on their membrane. They can be modified to improve tumor targeting or reduce the clearance of NPs by mononuclear phagocyte system (MPS) [148]. This study showed that tumor-derived EM-coated NPs have better homotypic targeting. The underlying mechanism of this phenomenon might be that tumor cell-derived EM have both the endosomal and plasma membrane protein, which makes EM-coated NPs have the dual function of avoiding immune clearance and targeting homologous tumors [149]. Although there have been limited reports on the use of microfluidic device for exosome engineering, due to the unique properties of exosome membranes and the flexible functions of microfluidic devices, this research field will have a great prospect in the future.

Using microfluidic device for preclinical evaluation of NPs has also shown advantages. The special design of channel geometry (such as line and cross shape microstructure) and highly controlled fluidics provides a high fluid mixing and avoids pure laminar flow and NPs sedimentation, thus increasing the internalization of NPs by the cells[139]. Because of the enhanced permeability and retention (EFR) effect, NPs often accumulate in tumors. The technical Tumor-Vasculature-on-a-Chip (TVOC) was reported to assessing NPs extravasation through leaky vasculature and their accumulation in tumor tissues, which provided a powerful platform for the preclinical evaluation on NPs [150]. Chen and colleagues recently developed a microfluidic platform that composed of the breast-cancer multicellular tumor spheroids (MCT) with uniform size, the endothelial monolayer and ECM, which better recapitulated the pathophysiological barrier and the blood microvessels in breast cancer microenvironment [151]. More than that, real-time monitoring on the chip through microplate reader is more accurate than conventional fluorescence detection [152-154]. On the strength of these features, the researchers synthesized a carbon dots (CDs) drug delivery system as a model to monitored drug delivery capacity and assessed in-situ cytotoxicity on the chip [151]. The results showed that this microfluidic platform give the possibilities of integrating useful characteristics of high-throughput and high spatio-temporal resolution in nano-drug evaluation.

\section{Exploring tumor heterogeneity on microfluidic chip}

Tumor heterogeneity is an ongoing challenge in cancer therapy, which can be divided into intertumoral heterogeneity and intratumoral heterogeneity. Intertumoral heterogeneity refers to the heterogeneity between different patients' tumors with the same histological type [155]. Intratumoral heterogeneity means genomic diversity within a single tumor [156]. A single tumor may contain different subclones, such as tumor-infiltrating cells, supportive cells and transformed cancer cells [157]. How to identify the heterogeneous clonal landscape of tumor and determine different drug combination regimens in different patients according to the situation of individual patients is a major problem in the realization of personalized therapy.

For single-cell sequencing, the main question we need to explain is that which gene or pathway defined cell status and how cell status affected disease [158]. The combination of microfluidic technique and high-throughput sequencing has been proved to be of great value for large scale analysis on single cell transcriptome. Captured and lysed a single cell is the first step on the single-cell sequencing carried out on microfluidic chip. Streets et al. developed an on-chip single-cell whole-transcriptome sequencing. After capturing and lysing cells, the mRNA with ploy A tail was reversely transcribed into cDNA and finally, using the next generation sequencing platform to collect the double-stranded cDNA for single-cell sequencing [159]. This model is of great significance and prospect for studying tumor heterogeneity because the detection sensitivity and measurement accuracy of mRNA have been significantly improved after the integration of microfluidic chip.

Targeting the specific oncogenic driver mutation gene can effectively inhibit tumor progression. For non-small cell lung cancer, patients with epidermal growth factor receptor (EGFR) mutation often choose EGFR tyrosine kinase inhibitors (TKIs) in clinical practice [160]. Therefore, the identification of EGFR mutations is crucial for targeted therapy [161]. Utilizing silicon-designed microwells on microfluidic chip, NSCLC cells was trapped into each microwell and imaging by immunofluorescent. After in situ lysing each cell, the cost-effective Sanger`s sequencing was used to find out multiple mutations [162]. EGFRmutated cells make up only a small proportion of the whole cancer cell population. This device has been proven to eliminate the noise of most un-mutated cells and accurately identify the mutation in which cell and determine whether different mutations co-exist in the 
same cell, providing reference for the clinical TKI selection. Similarly, the combination of the tri-states valve structure and Sanger's sequencing enabled high-throughput processing of multiple cells. With the integration of single cell capture, identification, lysis and in situ DNA MDA (Multiple Displacement Amplification) on a single chip, the statistical information on oncogenic mutations will be provided cost-effectively [163].

Besides single-cell sequencing, it has been reported that the lactate release level can be measured by microfluidic chip for sorting and identifying single cell. The level of lactate released by cancer cells during glycolysis is often related to the tumor metastasis, drug resistance and relapse [164, 165]. Mongersun et al. developed a microfluidic platform that utilized droplet to encapsulate a single cell. This platform measured not only extracellular lactate concentration, but also lactate release rate in the single-cell level. Under the chemical inhibition of lactate efflux, researchers identified the malignant cells and explored cancer metabolic pathway by studying the differences in two cancer cell lines [166]. Beyond that, droplet microfluidic chip usually needs surfactant to stabilize droplet formation. The droplet interfacial tension of a specific surfactant is sensitive to $\mathrm{pH}$. The relationship between interfacial tension and $\mathrm{pH}$ can affect the droplet flow, and thus the droplet contained live cells can be sorted [167]. The method of using interfacial tension on microfluidic chip to sort cancer cells in different metabolic status proposed a new idea for single cell analysis.

\section{Conclusions}

The biggest characteristic of microfluidic chip is the customizability, which means microfluidic chip is a very flexible scientific tool that can accommodate with advanced technologies. To date, microfluidic chip shows tremendous promise in cancer diagnosis and treatment. Microfluidic chip can be applied in everything from anticancer drug development and screening to cancer modeling and diagnosis. In recent years, the application of 3D printing in fabrication of microfluidic devices has made expensive photolithography no longer the only way to fabricate microfluidic chips. Because of the customizability and flexibility of microfluidic chip, establishing complicated tumor organoid on microfluidic chip is available, and patient-derived tumor tissue is able to be cultured and analyzed on a tiny chip.

There still exist some challenges on the development of microfluidic chip. The advantage of microfluidic chip is that it is easy to observe cell response and tumor morphology through imaging on microfluidic chips. For example, immunofluorescence is the most common method to analyze cell response on the chips. However, it is a challenge to collect cell samples from chips. In the process of sample collection, a number of chips need to be disassembled, which easily causes contamination of cell culture environment. At the same time, samples could be damaged in the collection process. This disadvantage hinders some experimental operations, such as immunohistochemistry. For this reason, a more reliable sample collection for microfluidic chip is urgently needed to be developed. In addition, PDMS is still the most commonly used material for microfluidic chips due to its excellent performance of biocompatibility, optical transparency, permeability, and the low cost. However, it has been reported that PDMS may exist physical or chemical reactions with certain reagents, and different PDMS formulations may have different interactions with different cells, which may bring trouble in some studies related to cell culture and drug screening. Although some obstacles can be overcome by adding specific coatings to culture region and other skills, developing new materials to fabricate microfluidic chips will bring us more options for scientific research.

In the past three decades, microfluidic chip has been rapidly developed. Although there are challenges need to be overcome, many achievements have been made in the field of cancer diagnosis and treatment. In the new era of personalized medicine, microfluidic chips should be developed toward accurate and point-of-care cancer diagnosis, bringing hope for personalized cancer treatment.

\section{Acknowledgements}

This work was supported by National Natural Science Foundation of China (U1903126 and 81773888), Natural Science Foundation of Guangdong Province (2020A151501005 and 2020A1515010605).

\section{Competing Interests}

The authors have declared that no competing interest exists.

\section{References}

1. Aboulkheyr Es H, Montazeri L, Aref AR, Vosough M, Baharvand H. Personalized Cancer Medicine: An Organoid Approach. Trends Biotechnol. 2018; 36: 358-71.

2. Hanahan D, Weinberg RA. Hallmarks of cancer: the next generation. Cell. 2011; 144: 646-74.

3. Yu F, Choudhury D. Microfluidic bioprinting for organ-on-a-chip models. Drug Discov Today. 2019; 24: 1248-57.

4. Sontheimer-Phelps A, Hassell BA, Ingber DE. Modelling cancer in microfluidic human organs-on-chips. Nat Rev Cancer. 2019; 19: 65-81.

5. Costa EC, Moreira AF, de Melo-Diogo D, Gaspar VM, Carvalho MP, Correia IJ. 3D tumor spheroids: an overview on the tools and techniques used for their analysis. Biotechnol Adv. 2016; 34: 1427-41.

6. Thoma CR, Zimmermann M, Agarkova I, Kelm JM, Krek W. 3D cell culture systems modeling tumor growth determinants in cancer target discovery. Adv Drug Deliv Rev. 2014; 69-70: 29-41. 
7. Aref AR, Campisi M, Ivanova E, Portell A, Larios D, Piel BP, et al. 3D microfluidic ex vivo culture of organotypic tumor spheroids to model immune checkpoint blockade. Lab Chip. 2018; 18: 3129-43.

8. Chen Y, Sun W, Kang L, Wang Y, Zhang M, Zhang H, et al. Microfluidic co-culture of liver tumor spheroids with stellate cells for the investigation of drug resistance and intercellular interactions. Analyst. 2019; 144: 4233-40.

9. Ko J, Ahn J, Kim S, Lee Y, Lee J, Park D, et al. Tumor spheroid-on-a-chip: a standardized microfluidic culture platform for investigating tumor angiogenesis. Lab Chip. 2019; 19: 2822-33.

10. Lee J-H, Kim S-K, Khawar IA, Jeong S-Y, Chung S, Kuh H-J. Microfluidic co-culture of pancreatic tumor spheroids with stellate cells as a novel 3D model for investigation of stroma-mediated cell motility and drug resistance. J Exp Clin Cancer Res. 2018; 37: 4.

11. Nath S, Devi GR. Three-dimensional culture systems in cancer research: Focus on tumor spheroid model. Pharmacol Ther. 2016; 163.

12. Zhuang J, Zhang J, Wu M, Zhang Y. A Dynamic 3D Tumor Spheroid Chip Enables More Accurate Nanomedicine Uptake Evaluation. Adv Sci (Weinh). 2019; 6: 1901462

13. Day C-P, Merlino G, Van Dyke T. Preclinical mouse cancer models: a maze of opportunities and challenges. Cell. 2015; 163: 39-53.

14. Dhiman N, Kingshott P, Sumer H, Sharma CS, Rath SN. On-chip anticancer drug screening - Recent progress in microfluidic platforms to address challenges in chemotherapy. Biosens Bioelectron. 2019; 137: 236-54.

15. Grskovic M, Javaherian A, Strulovici B, Daley GQ. Induced pluripotent stem cells--opportunities for disease modelling and drug discovery. Nat Rev Drug Discov. 2011; 10: 915-29.

16. Loskill $\mathrm{P}, \mathrm{Wu}$ JC. Stem cell based human organ-on-a-chip models for drug discovery and development. Adv Drug Deliv Rev. 2019; 140: 1-2.

17. Wnorowski A, Yang H, Wu JC. Progress, obstacles, and limitations in the use of stem cells in organ-on-a-chip models. Adv Drug Deliv Rev. 2019; 140.

18. Broutier L, Andersson-Rolf A, Hindley CJ, Boj SF, Clevers H, Koo B-K, et al. Culture and establishment of self-renewing human and mouse adult liver and pancreas 3D organoids and their genetic manipulation. Nat Protoc. 2016; 11: 1724-43.

19. Fujii M, Matano M, Toshimitsu K, Takano A, Mikami Y, Nishikori S, et al. Human Intestinal Organoids Maintain Self-Renewal Capacity and Cellular Diversity in Niche-Inspired Culture Condition. Cell Stem Cell. 2018; 23.

20. Takahashi Y, Sato S, Kurashima Y, Yamamoto T, Kurokawa S, Yuki Y, et al. A Refined Culture System for Human Induced Pluripotent Stem Cell-Derived Intestinal Epithelial Organoids. Stem Cell Reports. 2018; 10: 314-28.

21. Lancaster MA, Knoblich JA. Organogenesis in a dish: modeling development and disease using organoid technologies. Science. 2014; 345: 1247125.

22. Peela N, Truong D, Saini H, Chu H, Mashaghi S, Ham SL, et al. Advanced biomaterials and microengineering technologies to recapitulate the stepwise process of cancer metastasis. Biomaterials. 2017; 133: 176-207.

23. Yokota J. Tumor progression and metastasis. Carcinogenesis. 2000; 21: 497-503.

24. Hassell BA, Goyal G, Lee E, Sontheimer-Phelps A, Levy O, Chen CS, et al. Human Organ Chip Models Recapitulate Orthotopic Lung Cancer Growth, Therapeutic Responses, and Tumor Dormancy In vitro. Cell Rep. 2017; 21: 508-16.

25. Xu Z, Li E, Guo Z, Yu R, Hao H, Xu Y, et al. Design and Construction of a Multi-Organ Microfluidic Chip Mimicking the in vivo Microenvironment of Lung Cancer Metastasis. ACS Appl Mater Interfaces. 2016; 8: 25840-7.

26. Hao S, Ha L, Cheng G, Wan Y, Xia Y, Sosnoski DM, et al. A Spontaneous 3D Bone-On-a-Chip for Bone Metastasis Study of Breast Cancer Cells. Small. 2018; 14: e1702787.

27. Chen MB, Whisler JA, Fröse J, Yu C, Shin Y, Kamm RD. On-chip human microvasculature assay for visualization and quantification of tumor cell extravasation dynamics. Nat Protoc. 2017; 12: 865-80.

28. Jeon JS, Bersini S, Gilardi M, Dubini G, Charest JL, Moretti M, et al. Human 3D vascularized organotypic microfluidic assays to study breast cancer cell extravasation. Proc Natl Acad Sci USA. 2015; 112: 214-9.

29. Blaha L, Zhang C, Cabodi M, Wong JY. A microfluidic platform for modeling metastatic cancer cell matrix invasion. Biofabrication. 2017; 9: 045001

30. Terrell-Hall TB, Ammer AG, Griffith JIG, Lockman PR. Permeability across a novel microfluidic blood-tumor barrier model. Fluids Barriers CNS. 2017; 14: 3.

31. Lee H, Cho D-W. One-step fabrication of an organ-on-a-chip with spatial heterogeneity using a 3D bioprinting technology. Lab Chip. 2016; 16: 2618-25.

32. Da Silva K, Kumar P, Choonara YE, du Toit LC, Pillay V. 3D Printing of Extracellular Matrix (ECM)-Mimicking Scaffolds: A Critical Review of the Current ECM Materials. J Biomed Mater Res A. 2020

33. Lee H, Chae S, Kim JY, Han W, Kim J, Choi Y, et al. Cell-printed 3D liver-on-a-chip possessing a liver microenvironment and biliary system. Biofabrication. 2019; 11: 025001.

34. Zhang YS, Arneri A, Bersini S, Shin S-R, Zhu K, Goli-Malekabadi Z, et al. Bioprinting 3D microfibrous scaffolds for engineering endothelialized myocardium and heart-on-a-chip. Biomaterials. 2016; 110: 45-59.

35. Mi S, Du Z, Xu Y, Sun W. The crossing and integration between microfluidic technology and 3D printing for organ-on-chips. J Mater Chem B. 2018; 6: 6191-206.

36. Singh NK, Han W, Nam SA, Kim JW, Kim JY, Kim YK, et al. Three-dimensional cell-printing of advanced renal tubular tissue analogue. Biomaterials. 2020; 232: 119734 .
37. Polacheck WJ, Charest JL, Kamm RD. Interstitial flow influences direction of tumor cell migration through competing mechanisms. Proc Natl Acad Sci USA. 2011; 108: 11115-20.

38. Belgodere JA, King CT, Bursavich JB, Burow ME, Martin EC, Jung JP. Engineering Breast Cancer Microenvironments and 3D Bioprinting. Front Bioeng Biotechnol. 2018; 6: 66.

39. Li Y, Zhang T, Pang Y, Li L, Chen Z-N, Sun W. 3D bioprinting of hepatoma cells and application with microfluidics for pharmacodynamic test of Metuzumab. Biofabrication. 2019; 11: 034102

40. Radhakrishnan J, Varadaraj S, Dash SK, Sharma A, Verma RS. Organotypic cancer tissue models for drug screening: 3D constructs, bioprinting and microfluidic chips. Drug Discov Today. 2020

41. Rodrigues T, Kundu B, Silva-Correia J, Kundu SC, Oliveira JM, Reis RL, et al. Emerging tumor spheroids technologies for 3D in vitro cancer modeling. Pharmacol Ther. 2018; 184: 201-11.

42. Rana A, Zhang Y, Esfandiari L. Advancements in microfluidic technologies for isolation and early detection of circulating cancer-related biomarkers. Analyst. 2018; 143: 2971-91.

43. Wu L, Qu X. Cancer biomarker detection: recent achievements and challenges. Chem Soc Rev. 2015; 44: 2963-97.

44. Xu W, Xu M, Wang L, Zhou W, Xiang R, Shi Y, et al. Integrative analysis of DNA methylation and gene expression identified cervical cancer-specific diagnostic biomarkers. Signal Transduct Target Ther. 2019; 4: 55.

45. Sharma AK. Emerging trends in biomarker discovery: Ease of prognosis and prediction in cancer. Semin Cancer Biol. 2018; 52: iii-iiv.

46. Zieglschmid V, Hollmann C, Böcher O. Detection of disseminated tumor cells in peripheral blood. Crit Rev Clin Lab Sci. 2005; 42: 155-96.

47. Andree KC, Mentink A, Zeune LL, Terstappen LWMM, Stoecklein NH, Neves $\mathrm{RP}$, et al. Toward a real liquid biopsy in metastatic breast and prostate cancer: Diagnostic LeukApheresis increases CTC yields in a European prospective multicenter study (CTCTrap). Int J Cancer. 2018; 143: 2584-91.

48. Allard WJ, Matera J, Miller MC, Repollet M, Connelly MC, Rao C, et al. Tumor cells circulate in the peripheral blood of all major carcinomas but not in healthy subjects or patients with nonmalignant diseases. Clin Cancer Res. 2004; 10: 6897-904.

49. Talasaz AH, Powell AA, Huber DE, Berbee JG, Roh K-H, Yu W, et al. Isolating highly enriched populations of circulating epithelial cells and other rare cells from blood using a magnetic sweeper device. Proc Natl Acad Sci USA. 2009; 106: 3970-5.

50. Joosse SA, Pantel K. Biologic challenges in the detection of circulating tumor cells. Cancer research. 2013; 73 .

51. Dementeva N, Kokova D, Mayboroda OA. Current Methods of the Circulating Tumor Cells (CTC) Analysis: A Brief Overview. Curr Pharm Des. 2017; 23: 4726-8.

52. Nicolazzo C, Gradilone A, Loreni F, Raimondi C, Gazzaniga P. EpCAM Circulating Tumor Cells: Gold in the Waste. Dis Markers. 2019; 2019: 1718920.

53. Vona G, Sabile A, Louha M, Sitruk V, Romana S, Schütze K, et al. Isolation by size of epithelial tumor cells : a new method for the immunomorphological and molecular characterization of circulatingtumor cells. Am J Pathol. 2000; 156: 57-63

54. Ren X, Foster BM, Ghassemi P, Strobl JS, Kerr BA, Agah M. Entrapment of Prostate Cancer Circulating Tumor Cells with a Sequential Size-Based Microfluidic Chip. Anal Chem. 2018; 90: 7526-34

55. Park S, Ang RR, Duffy SP, Bazov J, Chi KN, Black PC, et al. Morphological differences between circulating tumor cells from prostate cancer patients and cultured prostate cancer cells. PLoS ONE. 2014; 9: e85264.

56. Choi H, Kim KB, Jeon CS, Hwang I, Lee S, Kim HK, et al. A label-free DC impedance-based microcytometer for circulating rare cancer cell counting. Lab Chip. 2013; 13: 970-7.

57. Gatenby RA, Gillies RJ. Why do cancers have high aerobic glycolysis? Nat Rev Cancer. 2004; 4: 891-9.

58. Hirschhaeuser F, Sattler UGA, Mueller-Klieser W. Lactate: a metabolic key player in cancer. Cancer research. 2011; 71: 6921-5.

59. Mani GK, Morohoshi M, Yasoda Y, Yokoyama S, Kimura H, Tsuchiya K. ZnO-Based Microfluidic pH Sensor: A Versatile Approach for Quick Recognition of Circulating Tumor Cells in Blood. ACS Appl Mater Interfaces. 2017; 9: 5193-203.

60. Ozkumur E, Shah AM, Ciciliano JC, Emmink BL, Miyamoto DT, Brachtel E, et al. Inertial focusing for tumor antigen-dependent and -independent sorting of rare circulating tumor cells. Sci Transl Med. 2013; 5: 179ra47.

61. Yan S, Zhang X, Dai X, Feng X, Du W, Liu B-F. Rhipsalis (Cactaceae)-like Hierarchical Structure Based Microfluidic Chip for Highly Efficient Isolation of Rare Cancer Cells. ACS Appl Mater Interfaces. 2016; 8: 33457-63.

62. de Wit S, Zeune LL, Hiltermann TJN, Groen HJM, Dalum Gv, Terstappen LWMM. Classification of Cells in CTC-Enriched Samples by Advanced Image Analysis. Cancers (Basel). 2018; 10.

63. Sinkala E, Sollier-Christen E, Renier C, Rosàs-Canyelles E, Che J, Heirich K, et al. Profiling protein expression in circulating tumour cells using microfluidic western blotting. Nat Commun. 2017; 8: 14622

64. Zhang Y, Wang Z, Wu L, Zong S, Yun B, Cui Y. Combining Multiplex SERS Nanovectors and Multivariate Analysis for In situ Profiling of Circulating Tumor Cell Phenotype Using a Microfluidic Chip. Small. 2018; 14: e1704433.

65. Hessvik NP, Llorente A. Current knowledge on exosome biogenesis and release. Cell Mol Life Sci. 2018; 75: 193-208 
66. Bayraktar R, Van Roosbroeck K, Calin GA. Cell-to-cell communication: microRNAs as hormones. Mol Oncol. 2017; 11: 1673-86.

67. Andre F, Schartz NEC, Movassagh M, Flament C, Pautier P, Morice P, et al. Malignant effusions and immunogenic tumour-derived exosomes. Lancet. 2002; 360: 295-305.

68. Momen-Heravi F. Isolation of Extracellular Vesicles by Ultracentrifugation. Methods Mol Biol. 2017; 1660: 25-32.

69. Oksvold MP, Neurauter A, Pedersen KW. Magnetic bead-based isolation of exosomes. Methods Mol Biol. 2015; 1218: 465-81.

70. Petersen KE, Shiri F, White T, Bardi GT, Sant H, Gale BK, et al. Exosome Isolation: Cyclical Electrical Field Flow Fractionation in Low-Ionic-Strength Fluids. Anal Chem. 2018; 90: 12783-90.

71. Zhang Z, Tang C, Zhao L, Xu L, Zhou W, Dong Z, et al. Aptamer-based fluorescence polarization assay for separation-free exosome quantification. Nanoscale. 2019; 11: 10106-13

72. Kang Y-T, Purcell E, Palacios-Rolston C, Lo T-W, Ramnath N, Jolly S, et al. Isolation and Profiling of Circulating Tumor-Associated Exosomes Using Extracellular Vesicular Lipid-Protein Binding Affinity Based Microfluidic Device. Small. 2019; 15: e1903600.

73. Zhang $\mathrm{P}$, Zhou X, Zeng Y. Multiplexed immunophenotyping of circulating exosomes on nano-engineered ExoProfile chip towards early diagnosis of cancer. Chem Sci. 2019; 10: 5495-504.

74. Zhao Z, Yang Y, Zeng Y, He M. A microfluidic ExoSearch chip for multiplexed exosome detection towards blood-based ovarian cancer diagnosis. Lab Chip. 2016; 16: 489-96.

75. Taller D, Richards K, Slouka Z, Senapati S, Hill R, Go DB, et al. On-chip surface acoustic wave lysis and ion-exchange nanomembrane detection of exosomal RNA for pancreatic cancer study and diagnosis. Lab Chip. 2015; 15: 1656-66.

76. Ayala-Mar S, Perez-Gonzalez VH, Mata-Gómez MA, Gallo-Villanueva RC, González-Valdez J. Electrokinetically Driven Exosome Separation and Concentration Using Dielectrophoretic-Enhanced PDMS-Based Microfluidics. Anal Chem. 2019; 91: 14975-82.

77. Wu M, Ouyang Y, Wang Z, Zhang R, Huang P-H, Chen C, et al. Isolation of exosomes from whole blood by integrating acoustics and microfluidics. Proc Natl Acad Sci USA. 2017; 114: 10584-9.

78. Contreras-Naranjo JC, Wu H-J, Ugaz VM. Microfluidics for exosome isolation and analysis: enabling liquid biopsy for personalized medicine. Lab Chip. 2017; 17: 3558-77.

79. Dorayappan KDP, Gardner ML, Hisey CL, Zingarelli RA, Smith BQ, Lightfoot MDS, et al. A Microfluidic Chip Enables Isolation of Exosomes and Establishment of Their Protein Profiles and Associated Signaling Pathways in Ovarian Cancer. Cancer research. 2019; 79: 3503-13.

80. Xu H, Liao C, Zuo P, Liu Z, Ye B-C. Magnetic-Based Microfluidic Device for On-Chip Isolation and Detection of Tumor-Derived Exosomes. Anal Chem. 2018; 90: 13451-8.

81. Lin S, Yu Z, Chen D, Wang Z, Miao J, Li Q, et al. Progress in Microfluidics-Based Exosome Separation and Detection Technologies for Diagnostic Applications. Small. 2020; 16: e1903916.

82. Schwarzenbach H, Hoon DSB, Pantel K. Cell-free nucleic acids as biomarkers in cancer patients. Nat Rev Cancer. 2011; 11: 426-37.

83. Han X, Wang J, Sun Y. Circulating Tumor DNA as Biomarkers for Cancer Detection. Genomics Proteomics Bioinformatics. 2017; 15: 59-72.

84. Diehl F, Schmidt K, Choti MA, Romans K, Goodman S, Li M, et al. Circulating mutant DNA to assess tumor dynamics. Nat Med. 2008; 14: 985-90.

85. Liu X-H, Sun M, Nie F-O, Ge Y-B, Zhang E-B, Yin D-D, et al. Lnc RNA HOTAIR functions as a competing endogenous RNA to regulate HER2 expression by sponging miR-331-3p in gastric cancer. Mol Cancer. 2014; 13: 92.

86. Anastasiadou E, Jacob LS, Slack FJ. Non-coding RNA networks in cancer. Nat Rev Cancer. 2018; 18

87. Huang W, Yan Y, Liu Y, Lin M, Ma J, Zhang W, et al. Exosomes with low miR-34c-3p expression promote invasion and migration of non-small cell lung cancer by upregulating integrin a2 $\beta 1$. Signal Transduct Target Ther. 2020; 5: 39 .

88. Kang J, Yu S, Lu S, Xu G, Zhu J, Yan N, et al. Use of a 6-miRNA panel to distinguish lymphoma from reactive lymphoid hyperplasia. Signal Transduct Target Ther. 2020; 5: 2

89. Underhill HR, Kitzman JO, Hellwig S, Welker NC, Daza R, Baker DN, et al. Fragment Length of Circulating Tumor DNA. PLoS Genet. 2016; 12: e1006162.

90. Campos CDM, Gamage SST, Jackson JM, Witek MA, Park DS, Murphy MC, et al. Microfluidic-based solid phase extraction of cell free DNA. Lab Chip. 2018; 18: 3459-70.

91. Ahrberg CD, Manz A, Chung BG. Polymerase chain reaction in microfluidic devices. Lab Chip. 2016; 16: 3866-84.

92. Li Z, Ju R, Sekine S, Zhang D, Zhuang S, Yamaguchi Y. All-in-one microfluidic device for on-site diagnosis of pathogens based on an integrated continuous flow PCR and electrophoresis biochip. Lab Chip. 2019; 19: 2663-8.

93. Ning Y, Cui X, Yang C, Jing F, Bian X, Yi L, et al. A self-digitization chip integrated with hydration layer for low-cost and robust digital PCR. Anal Chim Acta. 2019; 1055: 65-73.

94. Shen K-M, Sabbavarapu NM, Fu C-Y, Jan J-T, Wang J-R, Hung S-C, et al. An integrated microfluidic system for rapid detection and multiple subtyping of influenza A viruses by using glycan-coated magnetic beads and RT-PCR. Lab Chip. 2019; 19: 1277-86.
95. Wang $\mathrm{P}$, Jing $\mathrm{F}$, Li G, Wu Z, Cheng Z, Zhang J, et al. Absolute quantification of lung cancer related microRNA by droplet digital PCR. Biosens Bioelectron. 2015; 74: 836-42.

96. Wu Z, Bai Y, Cheng Z, Liu F, Wang P, Yang D, et al. Absolute quantification of DNA methylation using microfluidic chip-based digital PCR. Biosens Bioelectron. 2017; 96: 339-44.

97. Moltzahn F, Olshen AB, Baehner L, Peek A, Fong L, Stöppler H, et al. Microfluidic-based multiplex qRT-PCR identifies diagnostic and prognostic microRNA signatures in the sera of prostate cancer patients. Cancer research. 2011; 71: 550-60.

98. Aman R, Mahas A, Mahfouz M. Nucleic Acid Detection Using CRISPR/Cas Biosensing Technologies. ACS Synth Biol. 2020.

99. Kellner MJ, Koob JG, Gootenberg JS, Abudayyeh OO, Zhang F. SHERLOCK: nucleic acid detection with CRISPR nucleases. Nat Protoc. 2019: 14: 2986-3012.

100. Abudayyeh OO, Gootenberg JS, Konermann S, Joung J, Slaymaker IM, Cox $\mathrm{DBT}$, et al. C2c2 is a single-component programmable RNA-guided RNA-targeting CRISPR effector. Science. 2016; 353: aaf5573.

101. Li H, Yang Y, Hong W, Huang M, Wu M, Zhao X. Applications of genome editing technology in the targeted therapy of human diseases: mechanisms, advances and prospects. Signal Transduct Target Ther. 2020; 5: 1 .

102. Zhang J, You Y. CRISPR-Cas13a system: a novel approach to precision oncology. Cancer Biol Med. 2020; 17: 6-8.

103. Bruch R, Baaske J, Chatelle C, Meirich M, Madlener S, Weber W, et al. CRISPR/Cas13a-Powered Electrochemical Microfluidic Biosensor for Nucleic Acid Amplification-Free miRNA Diagnostics. Adv Mater Weinheim. 2019; 31: e1905311.

104. Labiris NR, Dolovich MB. Pulmonary drug delivery. Part I: physiological factors affecting therapeutic effectiveness of aerosolized medications. Br J Clin Pharmacol. 2003; 56: 588-99.

105. Miller PG, Chen C-Y, Wang YI, Gao E, Shuler ML. Multiorgan microfluidic platform with breathable lung chamber for inhalation or intravenous drug screening and development. Biotechnol Bioeng. 2020; 117: 486-97.

106. Astolfi M, Péant B, Lateef MA, Rousset N, Kendall-Dupont J, Carmona E, et al. Micro-dissected tumor tissues on chip: an ex vivo method for drug testing and personalized therapy. Lab Chip. 2016; 16: 312-25.

107. Kim S, Lee H, Chung M, Jeon NL. Engineering of functional, perfusable 3D microvascular networks on a chip. Lab Chip. 2013; 13: 1489-500.

108. Östman A, Corvigno S. Microvascular Mural Cells in Cancer. Trends Cancer. 2018; 4: 838-48.

109. Shirure VS, Bi Y, Curtis MB, Lezia A, Goedegebuure MM, Goedegebuure SP, et al. Tumor-on-a-chip platform to investigate progression and drug sensitivity in cell lines and patient-derived organoids. Lab Chip. 2018; 18: 3687-702.

110. Jeon H-J, Lee H, Yoon DS, Kim B-M. Dielectrophoretic force measurement of red blood cells exposed to oxidative stress using optical tweezers and a microfluidic chip. Biomed Eng Lett. 2017; 7: 317-23.

111. Babahosseini H, Misteli T, DeVoe DL. Microfluidic on-demand droplet generation, storage, retrieval, and merging for single-cell pairing. Lab Chip. 2019; 19: 493-502.

112. Huang W, Chang C-L, Brault ND, Gur O, Wang Z, Jalal SI, et al. Separation and dual detection of prostate cancer cells and protein biomarkers using a microchip device. Lab Chip. 2017; 17: 415-28.

113. Liu Z, Lee Y, Jang Jh, Li Y, Han X, Yokoi K, et al. Microfluidic cytometric analysis of cancer cell transportability and invasiveness. Sci Rep. 2015; 5: 14272.

114. Pandya HJ, Dhingra K, Prabhakar D, Chandrasekar V, Natarajan SK, Vasan $\mathrm{AS}$, et al. A microfluidic platform for drug screening in a $3 \mathrm{D}$ cancer microenvironment. Biosens Bioelectron. 2017; 94: 632-42.

115. Velasco V, Joshi K, Chen J, Esfandyarpour R. Personalized Drug Efficacy Monitoring Chip. Anal Chem. 2019; 91: 14927-35.

116. Kim HS, Waqued SC, Nodurft DT, Devarenne TP, Yakovlev VV, Han A. Raman spectroscopy compatible PDMS droplet microfluidic culture and analysis platform towards on-chip lipidomics. Analyst. 2017; 142: 1054-60.

117. Zhang Z, Chen Y-C, Cheng Y-H, Luan Y, Yoon E. Microfluidics 3D gel-island chip for single cell isolation and lineage-dependent drug responses study. Lab Chip. 2016; 16: 2504-12

118. Vaidyanathan R, Soon RH, Zhang P, Jiang K, Lim CT. Cancer diagnosis: from tumor to liquid biopsy and beyond. Lab Chip. 2018; 19: 11-34.

119. Fau MY, Maeda H. A new concept for macromolecular therapeutics in cancer chemotherapy: mechanism of tumoritropic accumulation of proteins and the antitumor agent smancs. Cancer Res. 1986; 46: 6387-92.

120. Song W, Musetti SN, Huang L. Nanomaterials for cancer immunotherapy. Biomaterials. 2017; 148: 16-30.

121. Singh AP, Biswas A, Shukla A, Maiti P. Targeted therapy in chronic diseases using nanomaterial-based drug delivery vehicles. Signal Transduct Target Ther. 2019; 4: 33.

122. Capretto L, Carugo D, Mazzitelli S, Nastruzzi C, Zhang X. Microfluidic and lab-on-a-chip preparation routes for organic nanoparticles and vesicular systems for nanomedicine applications. Adv Drug Deliv Rev. 2013; 65: 1496-532.

123. Maeki M, Kimura N, Sato Y, Harashima H, Tokeshi M. Advances in microfluidics for lipid nanoparticles and extracellular vesicles and applications in drug delivery systems. Adv Drug Deliv Rev. 2018; 128.

124. Forbes N, Hussain MT, Briuglia ML, Edwards DP, Horst JHT, Szita N, et al. Rapid and scale-independent microfluidic manufacture of liposomes 
entrapping protein incorporating in-line purification and at-line size monitoring. Int J Pharm. 2019; 556: 68-81.

125. Gdowski A, Johnson K, Shah S, Gryczynski I, Vishwanatha J, Ranjan A. Optimization and scale up of microfluidic nanolipomer production method for preclinical and potential clinical trials. J Nanobiotechnology. 2018; 16: 12.

126. Guimarães Sá Correia M, Briuglia ML, Niosi F, Lamprou DA. Microfluidic manufacturing of phospholipid nanoparticles: Stability, encapsulation efficacy, and drug release. Int J Pharm. 2017; 516: 91-9.

127. Bains A, Cao Y, Kly S, Wulff JE, Moffitt MG. Controlling Structure and Function of Polymeric Drug Delivery Nanoparticles Using Microfluidics. Mol Pharm. 2017; 14: 2595-606.

128. Ding S, Anton N, Vandamme TF, Serra CA. Microfluidic nanoprecipitation systems for preparing pure drug or polymeric drug loaded nanoparticles: an overview. Expert Opin Drug Deliv. 2016; 13: 1447-60.

129. Karnik R, Gu F, Basto P, Cannizzaro C, Dean L, Kyei-Manu W, et al. Microfluidic platform for controlled synthesis of polymeric nanoparticles. Nano Lett. 2008; 8: 2906-12.

130. Feng Q, Zhang L, Liu C, Li X, Hu G, Sun J, et al. Microfluidic based high throughput synthesis of lipid-polymer hybrid nanoparticles with tunable diameters. Biomicrofluidics. 2015; 9: 052604.

131. Wei W, Sun J, Guo X-Y, Chen X, Wang R, Qiu C, et al. Microfluidic-Based Holonomic Constraints of siRNA in the Kernel of Lipid/Polymer Hybrid Nanoassemblies for Improving Stable and Safe In vivo Delivery. ACS Appl Mater Interfaces. 2020; 12: 14839-54.

132. Jo W, Jeong D, Kim J, Cho S, Jang SC, Han C, et al. Microfluidic fabrication of cell-derived nanovesicles as endogenous RNA carriers. Lab Chip. 2014; 14: 1261-9.

133. Wang J, Li W, Zhang L, Ban L, Chen P, Du W, et al. Chemically Edited Exosomes with Dual Ligand Purified by Microfluidic Device for Active Targeted Drug Delivery to Tumor Cells. ACS Appl Mater Interfaces. 2017; 9: 27441-52.

134. Lu M, Ozcelik A, Grigsby CL, Zhao Y, Guo F, Leong KW, et al. Microfluidic Hydrodynamic Focusing for Synthesis of Nanomaterials. Nano Today. 2016; 11: 778-92.

135. Choi E, Kwon K, Kim D, Park J. An electrokinetic study on tunable 3D nanochannel networks constructed by spatially controlled nanoparticle assembly. Lab Chip. 2015; 15: 512-23.

136. Viefhues M, Eichhorn R, Fredrich E, Regtmeier J, Anselmetti D. Continuous and reversible mixing or demixing of nanoparticles by dielectrophoresis. Lab Chip. 2012; 12: 485-94.

137. Berenguel-Alonso M, Granados X, Faraudo J, Alonso-Chamarro J, Puyol M. Magnetic actuator for the control and mixing of magnetic bead-based reactions on-chip. Anal Bioanal Chem. 2014; 406: 6607-16.

138. Lee SH, van Noort D, Lee JY, Zhang B-T, Park TH. Effective mixing in a microfluidic chip using magnetic particles. Lab Chip. 2009; 9: 479-82.

139. Mitxelena-Iribarren O, Zabalo J, Arana S, Mujika M. Improved microfluidic platform for simultaneous multiple drug screening towards personalized treatment. Biosens Bioelectron. 2019; 123: 237-43.

140. Chiu Y-J, Cho SH, Mei Z, Lien V, Wu T-F, Lo Y-H. Universally applicable three-dimensional hydrodynamic microfluidic flow focusing. Lab Chip. 2013; 13: 1803-9.

141. Ran R, Middelberg APJ, Zhao C-X. Microfluidic synthesis of multifunctional liposomes for tumour targeting. Colloids Surf B Biointerfaces. 2016; 148: 402-10.

142. Deshpande S, Dekker C. On-chip microfluidic production of cell-sized liposomes. Nat Protoc. 2018; 13: 856-74.

143. Michelon M, Oliveira DRB, de Figueiredo Furtado G, Gaziola de la Torre L, Cunha RL. High-throughput continuous production of liposomes using hydrodynamic flow-focusing microfluidic devices. Colloids Surf B Biointerfaces. 2017; 156: 349-57.

144. Deng G, Sun Z, Li S, Peng X, Li W, Zhou L, et al. Cell-Membrane Immunotherapy Based on Natural Killer Cell Membrane Coated Nanoparticles for the Effective Inhibition of Primary and Abscopal Tumor Growth. ACS Nano. 2018; 12: 12096-108.

145. Fang RH, Hu C-MJ, Luk BT, Gao W, Copp JA, Tai Y, et al. Cancer cell membrane-coated nanoparticles for anticancer vaccination and drug delivery. Nano Lett. 2014; 14: 2181-8.

146. Li H, Jin K, Luo M, Wang X, Zhu X, Liu X, et al. Size Dependency of Circulation and Biodistribution of Biomimetic Nanoparticles: Red Blood Cell Membrane-Coated Nanoparticles. Cells. 2019; 8.

147. Xia Q, Zhang Y, Li Z, Hou X, Feng N. Red blood cell membrane-camouflaged nanoparticles: a novel drug delivery system for antitumor application. Acta Pharm Sin B. 2019; 9: 675-89.

148. Gilligan KE, Dwyer RM. Engineering Exosomes for Cancer Therapy. Int J Mol Sci. $2017 ; 18$

149. Liu C, Zhang W, Li Y, Chang J, Tian F, Zhao F, et al. Microfluidic Sonication To Assemble Exosome Membrane-Coated Nanoparticles for Immune Evasion-Mediated Targeting. Nano Lett. 2019; 19: 7836-44.

150. Wang H-F, Ran R, Liu Y, Hui Y, Zeng B, Chen D, et al. Tumor-Vasculature-on-a-Chip for Investigating Nanoparticle Extravasation and Tumor Accumulation. ACS Nano. 2018; 12: 11600-9.

151. Chen Y, Gao D, Wang Y, Lin S, Jiang Y. A novel 3D breast-cancer-on-chip platform for therapeutic evaluation of drug delivery systems. Anal Chim Acta. 2018; 1036 .
152. Albanese A, Lam AK, Sykes EA, Rocheleau JV, Chan WCW. Tumour-on-a-chip provides an optical window into nanoparticle tissue transport. Nat Commun. 2013; 4: 2718.

153. Friedrich J, Seidel C, Ebner R, Kunz-Schughart LA. Spheroid-based drug screen: considerations and practical approach. Nat Protoc. 2009; 4: 309-24.

154. Ozcelikkale A, Shin K, Noe-Kim V, Elzey BD, Dong Z, Zhang J-T, et al. Differential response to doxorubicin in breast cancer subtypes simulated by a microfluidic tumor model. J Control Release. 2017; 266: 129-39.

155. Dagogo-Jack I, Shaw AT. Tumour heterogeneity and resistance to cancer therapies. Nat Rev Clin Oncol. 2018; 15: 81-94.

156. Jamal-Hanjani M, Quezada SA, Larkin J, Swanton C. Translational implications of tumor heterogeneity. Clin Cancer Res. 2015; 21: 1258-66.

157. Prasetyanti PR, Medema JP. Intra-tumor heterogeneity from a cancer stem cell perspective. Mol Cancer. 2017; 16: 41.

158. Klein AM, Macosko E. InDrops and Drop-seq technologies for single-cell sequencing. Lab Chip. 2017; 17: 2540-1.

159. Streets AM, Zhang X, Cao C, Pang Y, Wu X, Xiong L, et al. Microfluidic single-cell whole-transcriptome sequencing. Proc Natl Acad Sci USA. 2014; 111: 7048-53.

160. Xu MJ, Johnson DE, Grandis JR. EGFR-targeted therapies in the post-genomic era. Cancer Metastasis Rev. 2017; 36: 463-73.

161. Wu S-G, Shih J-Y. Management of acquired resistance to EGFR TKI-targeted therapy in advanced non-small cell lung cancer. Mol Cancer. 2018; 17: 38.

162. Li R, Zhou M, Li J, Wang Z, Zhang $\mathrm{W}$, Yue $\mathrm{C}$, et al. Identifying EGFR-Expressed Cells and Detecting EGFR Multi-Mutations at Single-Cell Level by Microfluidic Chip. Nanomicro Lett. 2018; $10: 16$.

163. Li R, Zhou M, Yue C, Zhang W, Ma Y, Peng H, et al. Multiple single cell screening and DNA MDA amplification chip for oncogenic mutation profiling. Lab Chip. 2018; 18: 723-34.

164. Bhattacharya B, Low SHH, Soh C, Kamal Mustapa N, Beloueche-Babari M, $\mathrm{Koh} \mathrm{KX}$, et al. Increased drug resistance is associated with reduced glucose levels and an enhanced glycolysis phenotype. Br J Pharmacol. 2014; 171: 3255-67.

165. Morandi A, Indraccolo S. Linking metabolic reprogramming to therapy resistance in cancer. Biochim Biophys Acta Rev Cancer. 2017; 1868: 1-6.

166. Mongersun A, Smeenk I, Pratx G, Asuri P, Abbyad P. Droplet Microfluidic Platform for the Determination of Single-Cell Lactate Release. Anal Chem. 2016; 88: 3257-63.

167. Pan CW, Horvath DG, Braza S, Moore T, Lynch A, Feit C, et al. Sorting by interfacial tension (SIFT): label-free selection of live cells based on single-cell metabolism. Lab Chip. 2019; 19: 1344-51.

168. Li E, Xu Z, Liu F, Wang H, Wen J, Shao S, et al. Continual exposure to cigarette smoke extracts induces tumor-like transformation of human nontumor bronchial epithelial cells in a microfluidic chip. J Thorac Oncol. 2014; 9: 1091-100.

169. Choi Y, Hyun E, Seo J, Blundell C, Kim HC, Lee E, et al. A microengineered pathophysiological model of early-stage breast cancer. Lab Chip. 2015; 15: 3350-7.

170. Song J, Miermont A, Lim CT, Kamm RD. A 3D microvascular network model to study the impact of hypoxia on the extravasation potential of breast cell lines. Sci Rep. 2018; 8: 17949.

171. Sugimoto M, Kitagawa Y, Yamada M, Yajima $Y$, Utoh R, Seki M. Micropassage-embedding composite hydrogel fibers enable quantitative evaluation of cancer cell invasion under 3D coculture conditions. Lab Chip. 2018; 18: 1378-87.

172. Mi S, Liu Z, Du Z, Yi X, Sun W. Three-dimensional microfluidic tumor-macrophage system for breast cancer cell invasion. Biotechnol Bioeng. 2019; 116: 1731-41.

173. Truong DD, Kratz A, Park JG, Barrientos ES, Saini H, Nguyen T, et al. A Human Organotypic Microfluidic Tumor Model Permits Investigation of the Interplay between Patient-Derived Fibroblasts and Breast Cancer Cells. Cancer research. 2019; 79: 3139-51.

174. Toh Y-C, Raja A, Yu H, van Noort D. A 3D Microfluidic Model to Recapitulate Cancer Cell Migration and Invasion. Bioengineering (Basel). 2018; 5.

175. Aung A, Theprungsirikul J, Lim HL, Varghese S. Chemotaxis-driven assembly of endothelial barrier in a tumor-on-a-chip platform. Lab Chip. 2016; 16: 1886-98.

176. Skardal A, Devarasetty M, Forsythe S, Atala A, Soker S. A reductionist metastasis-on-a-chip platform for in vitro tumor progression modeling and drug screening. Biotechnol Bioeng. 2016; 113: 2020-32.

177. Aleman J, Skardal A. A multi-site metastasis-on-a-chip microphysiological system for assessing metastatic preference of cancer cells. Biotechnol Bioeng. 2019; 116: 936-44.

178. Ong LJY, Islam A, DasGupta R, Iyer NG, Leo HL, Toh Y-C. A 3D printed microfluidic perfusion device for multicellular spheroid cultures. Biofabrication. 2017; 9: 045005.

179. Zhou X, Zhu W, Nowicki M, Miao S, Cui H, Holmes B, et al. 3D Bioprinting a Cell-Laden Bone Matrix for Breast Cancer Metastasis Study. ACS Appl Mater Interfaces. 2016; 8: 30017-26.

180. Zhao Z, McGill J, Gamero-Kubota P, He M. Microfluidic on-demand engineering of exosomes towards cancer immunotherapy. Lab Chip. 2019; 19: 1877-86.

181. Kadimisetty K, Malla S, Bhalerao KS, Mosa IM, Bhakta S, Lee NH, et al. Automated 3D-Printed Microfluidic Array for Rapid Nanomaterial-Enhanced Detection of Multiple Proteins. Anal Chem. 2018; 90: 7569-77. 
182. Bsoul A, Pan S, Cretu E, Stoeber B, Walus K. Design, microfabrication, and characterization of a moulded PDMS/SU-8 inkjet dispenser for a Lab-on-a-Printer platform technology with disposable microfluidic chip. Lab Chip. 2016; 16: 3351-61.

183. Nagrath S, Sequist LV, Maheswaran S, Bell DW, Irimia D, Ulkus L, et al. Isolation of rare circulating tumour cells in cancer patients by microchip technology. Nature. 2007; 450: 1235-9.

184. Helzer KT, Barnes HE, Day L, Harvey J, Billings PR, Forsyth A. Circulating tumor cells are transcriptionally similar to the primary tumor in a murine prostate model. Cancer research. 2009; 69: 7860-6.

185. Stott SL, Hsu C-H, Tsukrov DI, Yu M, Miyamoto DT, Waltman BA, et al. Isolation of circulating tumor cells using a microvortex-generating herringbone-chip. Proc Natl Acad Sci USA. 2010; 107: 18392-7.

186. Shi W, Wang S, Maarouf A, Uhl CG, He R, Yunus D, et al. Magnetic particles assisted capture and release of rare circulating tumor cells using wavy-herringbone structured microfluidic devices. Lab Chip. 2017; 17: 3291-9.

187. Que Z, Luo B, Zhou Z, Dong C, Jiang Y, Wang L, et al. Establishment and characterization of a patient-derived circulating lung tumor cell line in vitro and in vivo. Cancer Cell Int. 2019; 19: 21.

188. Wang S, Thomas A, Lee E, Yang S, Cheng X, Liu Y. Highly efficient and selective isolation of rare tumor cells using a microfluidic chip with wavy-herringbone micro-patterned surfaces. Analyst. 2016; 141: 2228-37.

189. Jiang X, Wong KHK, Khankhel AH, Zeinali M, Reategui E, Phillips MJ, et al. Microfluidic isolation of platelet-covered circulating tumor cells. Lab Chip. 2017; 17: 3498-503.

190. Park M-H, Reátegui E, Li W, Tessier SN, Wong KHK, Jensen AE, et al. Enhanced Isolation and Release of Circulating Tumor Cells Using Nanoparticle Binding and Ligand Exchange in a Microfluidic Chip. J Am Chem Soc. 2017; 139: 2741-9.

191. Gleghorn JP, Pratt ED, Denning D, Liu H, Bander NH, Tagawa ST, et al. Capture of circulating tumor cells from whole blood of prostate cancer patients using geometrically enhanced differential immunocapture (GEDI) and a prostate-specific antibody. Lab Chip. 2010; 10: 27-9.

192. Franses JW, Philipp J, Missios P, Bhan I, Liu A, Yashaswini C, et al. Pancreatic circulating tumor cell profiling identifies LIN28B as a metastasis driver and drug target. Nat Commun. 2020; 11: 3303.

193. Kalinich M, Bhan I, Kwan TT, Miyamoto DT, Javaid S, LiCausi JA, et al. An RNA-based signature enables high specificity detection of circulating tumor cells in hepatocellular carcinoma. Proc Natl Acad Sci USA. 2017; 114: 1123-8.

194. Karabacak NM, Spuhler PS, Fachin F, Lim EJ, Pai V, Ozkumur E, et al. Microfluidic, marker-free isolation of circulating tumor cells from blood samples. Nat Protoc. 2014; 9: 694-710.

195. Chen H. A Triplet Parallelizing Spiral Microfluidic Chip for Continuous Separation of Tumor Cells. Sci Rep. 2018; 8: 4042

196. Garcia J, Barthelemy D, Geiguer F, Ballandier J, Li KW, Aurel J-P, et al. Semi-automatic PD-L1 Characterization and Enumeration of Circulating Tumor Cells from Non-small Cell Lung Cancer Patients by Immunofluorescence. J Vis Exp. 2019.

197. Kulasinghe A, Tran THP, Blick T, O'Byrne K, Thompson EW, Warkiani ME, et al. Enrichment of circulating head and neck tumour cells using spiral microfluidic technology. Sci Rep. 2017; 7: 42517.

198. Kulasinghe A, Zhou J, Kenny L, Papautsky I, Punyadeera C. Capture of Circulating Tumour Cell Clusters Using Straight Microfluidic Chips. Cancers (Basel). 2019; 11.

199. Zhou J, Kulasinghe A, Bogseth A, O'Byrne K, Punyadeera C, Papautsky I. Isolation of circulating tumor cells in non-small-cell-lung-cancer patients using a multi-flow microfluidic channel. Microsyst Nanoeng. 2019; 5: 8 .

200. Loeian MS, Mehdi Aghaei S, Farhadi F, Rai V, Yang HW, Johnson MD, et al. Liquid biopsy using the nanotube-CTC-chip: capture of invasive CTCs with high purity using preferential adherence in breast cancer patients. Lab Chip. 2019; 19: 1899-915. 